\title{
Recent insights in magnetic hyperthermia: From the "hot-spot" effect for local delivery to combined magneto-photo-thermia using magneto- plasmonic hybrids
}

\author{
Esther Cazares-Cortes ${ }^{\mathrm{a}, 1}$, Sonia Cabana ${ }^{\mathrm{a}, \mathrm{b}, 1}$, Charlotte Boitard ${ }^{\mathrm{a}}$, Emilie Nehlig a , Nébéwia Griffete ${ }^{\mathrm{a}}$, \\ Jérôme Fresnais $^{\mathrm{a}}$, Claire Wilhelm ${ }^{\mathrm{b}}$, Ali Abou-Hassan ${ }^{\mathrm{a}, *}$, Christine Ménager ${ }^{\mathrm{a}, *}$ \\ a Sorbonne Université, CNRS, PHysico-chimie des Electrolytes et Nanosystèmes InterfaciauX, PHENIX, F-75005 Paris, France \\ b Laboratoire Matière et Systèmes Complexes (MSC), UMR 7057, CNRS, Université Paris Diderot, 75205 Paris Cedex 05, France
}

Keywords:

Magnetic nanoparticles

Local magnetic hyperthermia

Drug release

Combined therapy

Micro and nanogels

Molecularly imprinted polymers

Magneto-plasmonic nanosystems

\begin{abstract}
A B S T R A C T
Magnetic hyperthermia which exploits the heat generated by magnetic nanoparticles (MNPs) when exposed to an alternative magnetic field (AMF) is now in clinical trials for the treatment of cancers. However, this thermal therapy requires a high amount of MNPs in the tumor to be efficient. On the contrary the hot spot local effect refers to the use of specific temperature profile at the vicinity of nanoparticles for heating with minor to no long-range effect. This magneto-thermal effect can be exploited as a relevant external stimulus to temporally and spatially trigger drug release.

In this review, we focus on recent advances in magnetic hyperthermia. Indirect experimental proofs of the local temperature increase are first discussed leading to a good estimation of the temperature at the surface (from 0.5 to $6 \mathrm{~nm}$ ) of superparamagnetic NPs. Then we highlight recent studies illustrating the hot-spot effect for drugrelease. Finally, we present another recent strategy to enhance the efficacity of thermal treatment by combining photothermal therapy with magnetic hyperthermia mediated by magneto-plasmonic nanoplatforms.
\end{abstract}

\section{Contents}

1. Introduction . . . . . . . . . . . . . . . . . . . . . . . . . . . . . . . . . . . . . . . . . . . . 233

2. Magnetic hyperthermia for remotely triggered drug delivery in athermal conditions . . . . . . . . . . . . . . . . . . . . . 234

2.1. The hot spot effect . . . . . . . . . . . . . . . . . . . . . . . . . . . . . . . . . . . . . . . . . 234

2.2. Magnetic thermoresponsive polymeric nanosystems . . . . . . . . . . . . . . . . . . . . . . . . . . 236

2.2.1. Synthesis of thermosensitive magnetic micro and nanogels . . . . . . . . . . . . . . . . . . . . . . . . . . . . . 236

2.2.2. Drug delivery under AMF. . . . . . . 236

2.2.3. In vivo drug release under AMF . . . . . . . . . . . . . . . . . . . . . . . . . . . . . . . . . . . . . . . . . 237

2.3. Molecularly imprinted polymer ... . . . . . . . . . . . . . . . . . . . . . . . . . . . . . . 238

3. Increasing the heat delivered per nanoparticles . . . . . . . . . . . . . . . . . . . . . . . . . . . . . . . . . . . . . . . . . . . . 239

3.1. Magnetoplasmonic NPs. . . . . . . . . . . . . . . . . . . . . . . . . . . . . . . . . . . . . . 239

3.1.1. Synthesis of magnetoplasmonic nanohybrids . . . . . . . . . . . . . . . . . . . . . . . . . . . . . . . . . . . . . . . . . . . 240

3.1.2. Magnetoplasmonic $\mathrm{Fe}_{3} \mathrm{O}_{4} @ \mathrm{au}$ for thermal therapies . . . . . . . . . . . . . . . . . . . . . . . . . . . . . . . . . . . . 240

4. Conclusion and outlook . . . . . . . . . . . . . . . . . . . . . . . . . . . . . . . . . . . . . . . . . . . . . . . 243

References . . . . . . . . . . . . . . . . . . . . . . . . . . . . . . . . . . . . . . . . . . . . . 243

\footnotetext{
* Corresponding authors.

E-mail addresses: ali.abou_hassan@sorbonne-universite.fr (A. Abou-Hassan), christine.menager@sorbonne-universite.fr (C. Ménager).

1 Authors contributed equally.
}

\section{Introduction}

Magnetic hyperthermia (MHT) is a type of thermal cancer treatment that takes advantage of the heat generated by magnetic nanoparticles 
(MNPs). MHT has been extensively investigated both theoretically and experimentally to reach a therapeutic efficacy. Activating the MNPs located deep inside the tissues or organs by MHT can be accomplished at frequencies $(f)$ and field $(\mathrm{H})$ conditions that do not harm the human body $\left(\mathrm{H} \times f \leq 5 \times 10^{8} \mathrm{~A} / \mathrm{m} . \mathrm{s}\right)[1]$

When exposed to alternative magnetic field (AMF) of appropriate amplitude and frequency, MNPs release heat, which reduces the viability of cancer cells through apoptotic or necrotic pathways. Such nanothermo-therapy is already in clinical trials (e.g. phase II for glioblastoma multiforme, MagForce, Berlin, http://www.magforce.de/en/home.html) and received a European market authorization. [2]

For superparamagnetic MNPs, magnetic loss responsible for converting magnetic energy into heat under AMF is attributed to Néel-Brown relaxations. [3] Magnetic heating is attractive as a physical modality for cancer treatment due to specific features such as non-invasiveness, no depth penetration limit, remote controllability, nanoscale spatial resolution, and molecular-level specificity. However, magnetic hyperthermia still suffers from critical drawbacks, including the need for a high dose of MNPs (usually 1-2 M, which is a few orders of magnitude larger than contrast agent used for MRI) or therapeutic resistance arising from self-protective mechanisms of cancer cells against the applied thermal stress.

In recent years, in order to overcome such limitations, new approaches based on multimodal synergistic therapy, employing the integration of two or more form of treatment, were developed. [4]

Multimodal synergistic therapy is defined as the cooperation among different treatments integrated into a single nanoplatform whose yields enhanced therapeutic effects compared to the individual treatments.

The combination of multiple modalities in a single system is possible thanks to a smart design of multifunctional nanomaterials. The first approach for multimodal therapy is to combine a physical treatment (MHT, photothermal therapy (PTT), high intensity focused ultrasound (HIFU) and others) and a chemotherapy in the same platforms. Numerous magnetic systems were designed to trigger drug release by MHT but only few of them managed to release the drug by hot spot local effect, meaning in global athermal conditions.

In this review we will first focus on the heat generated by MNPs at the nanometer scale to magnetically induce drug release from polymeric platform. This local heat delivery and subsequent therapeutic drug release is complementary to single-handed MHT. Besides, AMF may provide remote regulation of the amount of drug release, enhancement of the therapeutic effectiveness and decrease of systemic toxicity, notably through spatial and temporal control of drug release. Second, we will present another recent strategy to enhance the efficacy of thermal treatment, by combining PTT with MHT, mediated by magnetoplasmonic nanoplatforms.

\section{Magnetic hyperthermia for remotely triggered drug delivery in athermal conditions}

\subsection{The hot spot effect}

The last 20 years have witnessed an important increase in the number of reports dedicated to magnetic hyperthermia. Many have focused on the "hot spot effect" which refers to the use of specific temperature profile at the vicinity of nanoparticles (nano-assemblies) for heating with minor to no long-range (macroscopic) effect. Such an approach has numerous advantages. First, the effect becomes less dependent on the number of nanoparticles usually required to increase significantly the macroscopic temperature in the targeted area. Hence, no major stress is applied to the biological environment, allowing a better recovery of neighboring healthy cells or organs. The toxicity is thus strongly limited and side-effects of magnetic nanoparticles are dramatically reduced. Secondly, the thermal profile around the nanoparticles can induce drug release without thermally damaging the areas of interest. Once again, side-effects should be limited. Additionally, nanoparticle aggregation, that often occurs in cellular environment and limits the macroscopic heating efficiency of magnetic nanoparticles, should not impact the local temperature effect as it impacts the macroscopic heating efficiency [5-7].

Last, very local effects can be triggered, without damaging other organelles within the cells. For instance, Huang et al. demonstrated that nanoparticles targeted to the outer membrane of cells can activate ions channels with very local temperature increase without thermally affecting the Golgi apparatus [8].

Hot spot effect requires evidence of the heating efficiency at the local stage. These proofs could be indirect (evaluation of a thermal effect to a physical property) or a direct evaluation of the thermal gradient in the area of interest. Most recent publications elucidate the indirect role of local heat generation.

Most "hot spot" effects are triggered by thermosensitive reactions. N'Guyen et al. described a retro-Diels-Alder reaction conducted through hyperthermia excitation on maghemite nanoparticles functionalized with multifunctional ligands that use maleimide to link a furanterminated moiety as thermosensitive linkers [9]. They evidenced a fluorophore release proportional to the excitation duration and the nanoparticles concentration, with no macroscopic temperature increase. The same retro-Diels-Alder reactions were used and monitored by magnetic hyperthermia on $\left(\mathrm{Zn}_{0.4} \mathrm{Mn}_{0.6}\right) \mathrm{Fe}_{2} \mathrm{O}_{4}$ magnetic nanoparticles in mesoporous silica employed as cargo by Rühle et al. [10] The pores of the cargos were closed with molecules that act as nanovalves and could liberate the payload by the thermosensitive reaction. This reaction allowed to control the molecular release above $65^{\circ} \mathrm{C}$, as shown in Fig. 1. Jaque et al. explored new nanothermometric methods combining light emission properties of luminescent nanoparticles in the NearInfrared (NIR) range with nanoheaters under magnetic field. [11]

The release of fluorescein with AMF stimulation demonstrated that the surface temperature of the cargos reaches at least $65{ }^{\circ} \mathrm{C}$, about $20 \mathrm{~nm}$ apart from the magnetic particle surface.

Thermosensitive block copolymers were also reported for surface functionalization of magnetic nanoparticles by Polo-Corrales and Rinaldi [12]. The authors demonstrated that a rapid temperature increase occurs in the immediate vicinity of the nanoparticles while the macroscopic temperature increases more slowly in the bulk. They concluded that their polymer (PNIPAM) crossed the lower critical solution temperature (LCST) even though the medium has not reached this critical value. Very recently grafting molecularly imprinted polymers (MIP) on iron oxide nanoparticles was reported by Griffete et al. for drug delivery applications [13]. The release of doxorubicin was significantly increased when particles were submitted to the AMF stimulation [13]. The release rate was comparable to the one obtained at temperature higher than $50{ }^{\circ} \mathrm{C}$, which gave an evaluation of the mean temperature in the polymer corona around the magnetic core $(10-30 \mathrm{~nm})$. More recently, the direct radical polymerization of the MIP layer through hyperthermia excitation at moderate temperature was also evidenced by the same group [14]. This polymerization usually occurs at $60^{\circ} \mathrm{C}$, but it could be achieved at temperature below $31^{\circ} \mathrm{C}$ under magnetic activation, confirming the temperature increase proposed in the previous work. Similar results were obtained by Guisasola et al. who elaborated nanocarriers made of iron oxide nanoparticles embedded in a silica shell loaded with fluorescein and modified with an outer shell of thermosensitive polymer (NIPAM/NHMA) [15]. In this nanoarchitecture, despite the fact that the iron oxide core is $20 \mathrm{~nm}$ away from the surface of the carrier, LCST transition was observed under magnetic stimulation. Moreover, the release of fluorescein was demonstrated to be more efficient in isothermal condition with magnetic stimulation than with macroscopic heating.

Taken together, these results show that local thermal effect could be of outmost importance for the next generation of magnetic carriers for therapeutic applications. These systems will need a more careful characterization and nano-investigations toward specific and controlled effects. 
(a)

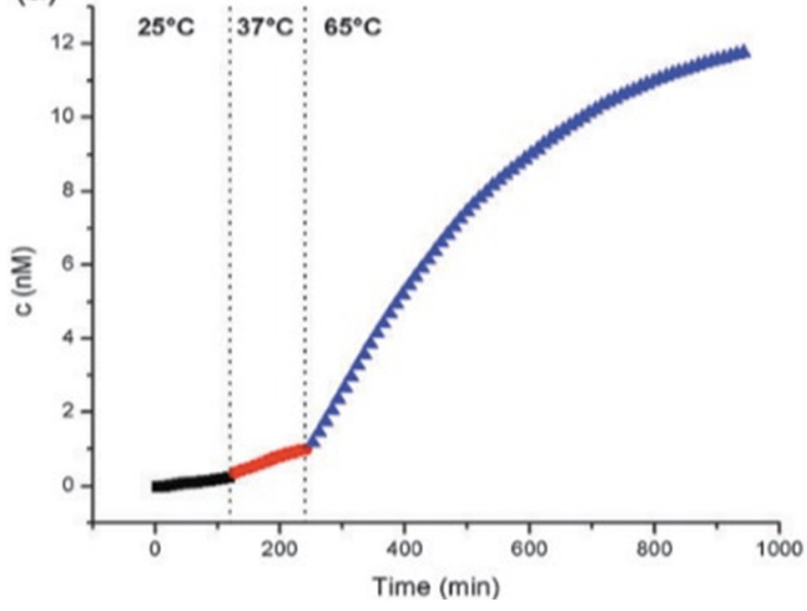

(b)

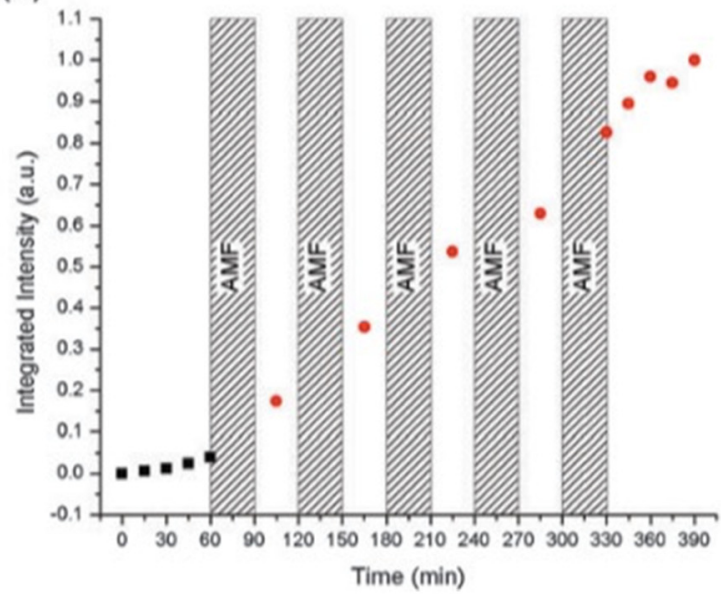

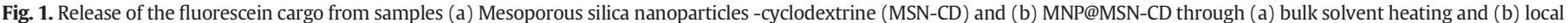
sheating. Reprinted with permission from [10].

While the "hot-spot" effect has started to be explored indirectly from macroscopic observations of nanoscale-derived effects, the direct evaluation at the nanoscale of the local temperature profile around the nanoparticles is less investigated. To reach such information Dong and Zink used the dependence of fluorescence on up-conversion emission spectrum of $\mathrm{NaYF}_{4}: \mathrm{Yb}^{3+}, \mathrm{Er}^{3+}$ nanoparticles embedded into mesoporous silica matrix with magnetic particles [16]. The temperature was measured in the silica matrix, but without precision on the temperature around the magnetic nanoparticle. However, compared to bulk where a temperature increase of only $20^{\circ} \mathrm{C}$ was observed, the authors distinguished a more rapid temperature increase, reaching up to $45^{\circ} \mathrm{C}$ above the starting temperature around the nanoparticles. Even though the gradient of temperature was not elucidated exactly at the surface of magnetic nanoparticles, this proof of concept is of prime importance to establish temperature profile in the vicinity of hot spots.

Alternatively, DNA coupled with fluorophores can be also used as a local thermometer [17]. Gareau et al. demonstrated that nonexpensive DNA strands could be used with good sensitivity $\left(0.05{ }^{\circ} \mathrm{C}\right)$ in a large range of temperature $\left(30^{\circ} \mathrm{C}\right.$ to $\left.85^{\circ} \mathrm{C}\right)$. They showed that the combination of thermoswitches allows large gain of fluorescence for very low temperature variation. This strategy could benefit to the temperature measurement around hot spots. Equivalently, Dias et al. used the hybridization of DNA to measure precisely the temperature at the surface of iron oxide nanoparticles [18]. They were able to report variations of temperature (in comparison to the macroscopic one) of $8.3^{\circ} \mathrm{C}$ at $5 \mathrm{~nm}$ from the nanoparticle surface to $6.1{ }^{\circ} \mathrm{C}$ at $5.6 \mathrm{~nm}$.

Another example on the use of DNA is given by Yu et al. [19]. The authors evaluated the thermodynamic equilibrium between the hybridization and denaturation of double-stranded DNA. This strategy is less straightforward because it needs the separation of the unlinked DNA strands from the bulk dispersion ("rapid" separation is achieved). On the more, their results depend strongly on the excitation time, and the temperature increase between the surface of the nanoparticles and the bulk is reported to be approximatively $50-60{ }^{\circ} \mathrm{C}$, with no direct determination of the exact distance of the DNA from the surface. It is just stated that the difference in temperature is given "at the surface" compared to the bulk.

Polymers can also be used as spacers between the surface of iron oxide nanoparticles and a thermo-sensitive linker. Riedinger et al. prepared $15 \mathrm{~nm}$ diameter iron oxide nanoparticles coated with polyethylene glycol (PEG) oligomer terminated by a fluoresceine-amine dye attached to a thermolabile azo linker [20]. The length of the PEG was modified from $500 \mathrm{~g} / \mathrm{mol}$ to $1500 \mathrm{~g} / \mathrm{mol}$, and $8000 \mathrm{~g} / \mathrm{mol}$. These molecular weights allowed to reach different distances from the surface of the nanoparticle: $0.47 \mathrm{~nm}, 0.83 \mathrm{~nm}$, and $1.9 \mathrm{~nm}$. The temperature increases (above the bulk temperature) measured at those distances are $42{ }^{\circ} \mathrm{C}$, $26^{\circ} \mathrm{C}$, and $11{ }^{\circ} \mathrm{C}$, respectively. In this example, the distances are closer to the surface of the particles, compared to the work of Dias et al. who recorded the temperature at 5-6 $\mathrm{nm}$ from the surface.

These nanoparticles were not synthesized by the same method, have different sizes, and different magnetic excitation parameters (magnetic field amplitudes and frequencies). However, all results collapse to a unique image showing a strong thermal gradient from the surface of the nanoparticles to the surrounding medium (Fig. 2). A unique study combining short and large distance measurements on the same system is still missing. Interestingly, in another study made in our group, with another system involving AMF-mediated thermo-polymerization at the surface of MNPs, the extrapolation of the temperature profile, yet less resolved, is in good agreement with the reported data of Fig. 2.

Finally, we must emphasize that, while MHT has been extensively studied for thermal therapy and drug delivery, exploring the "hotspot" effect is still in its infancy. Hybrid materials combining a magnetic and a polymeric component (thermoresponsive, molecularly imprinted) have shown to be very promising for local heating applications in drug delivery and hyperthermia therapy and will be reviewed thoroughly in the following sections of this paper.

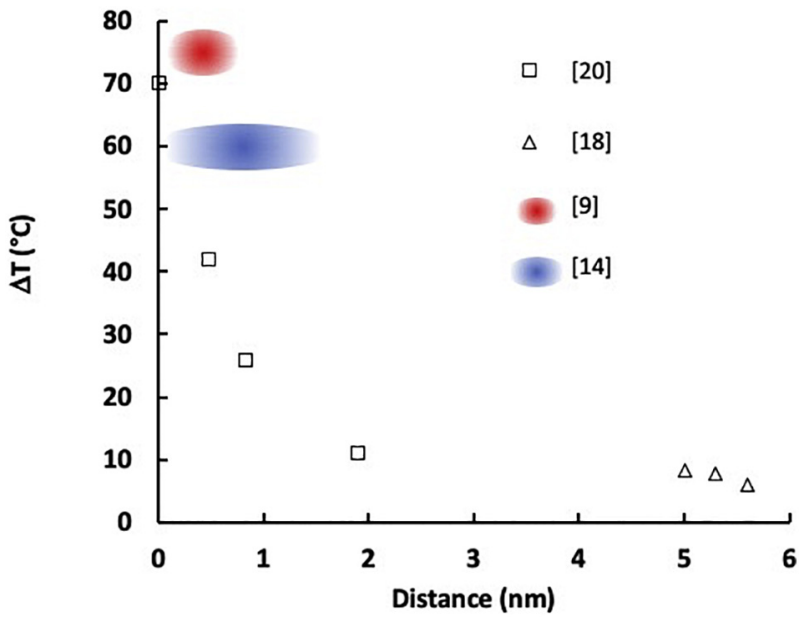

Fig. 2. Comparison of the temperature variation reported by Riedinger et al. [20], Dias et al. [18], Griffete et al. [14], and N'Guyen 9 Reproduced with permission from ref. [14,18,20,9] respectively. 


\subsection{Magnetic thermoresponsive polymeric nanosystems}

In the last few years, triggered drug delivery, especially using AMF [21], attracted a lot of attention. Magnetic mesoporous silica nanoparticles were the main focus of numerous studies, as they are a promising platform for cancer therapy [22] due to their potential in chemotherapeutic drug delivery and hyperthermia therapy under an AMF. For example, Ruiz-Hernandez et al. synthesized $\gamma-\mathrm{Fe}_{2} \mathrm{O}_{3} /$ mesoporous silica microspheres, and found that these magnetic microspheres showed a sustained drug release behavior and ability to generate heat under a low-frequency AMF [23]. Alternatively Lu et al. reported the preparation of $100 \mathrm{~nm}$ magnetic hollow mesoporous silica nanocapsules, and these nanocapsules showed magnetic field induced heating and remotely triggered drug release capabilities, which is promising for the combination of hyperthermia and chemotherapy [24]. The applications of silicabased nanomaterials in drug delivery and nanotherapy applications have been reviewed elsewhere [25,26], herein we will only focus on organic polymer based materials as micro- and nano-gels and molecularly imprinted polymer which, when combined with MNPs, offer intriguing opportunities regarding the development of a novel class of nanomaterials for drug delivery.

Due to their versatile macromolecular structures, polymers can serve as flexible nanoplatforms. A large portfolio of polymers with interesting physico-chemical properties have been developed with a special focus on those that exhibit structural or conformational changes in response to different stimuli. The release of drug can be achieved either by local biological stimuli ( $\mathrm{pH}$, redox, enzymes) or by externally applied radiation (light/electromagnetic fields, focused ultrasound). However biological environments offer no possibility of remote activation or dose control over drug release, contrary to external triggers which present advantages to achieve drug release with spatiotemporal and/or on demand control.

A highly comprehensive review dealing with the remote release by AMF of different drug delivery nanoplatforms (liposomes, polymersomes, capsules) has been published elsewhere [27]. Local drug delivery controlled by an external stimulus using nanoparticulate systems has emerged as a very promising strategy for nanomedicine. However, this requires a specific and well-controlled design.

\subsubsection{Synthesis of thermosensitive magnetic micro and nanogels}

Thermosensitive magnetic micro and nanogels are crosslinked polymer networks, capable of absorbing large quantities of drugs and water in the swelling state, and containing magnetic nanoparticles, that can be heated when exposed to an alternative magnetic field. In any case, the drug release is activated by an AMF-generated local heating (at nmscale) which may be mutualized with magnetic hyperthermia if macroscopic temperature elevation reaches a threshold, typically $43{ }^{\circ} \mathrm{C}$. In other words, magnetically induced drug release can occur in the local "hot spot" condition without macroscopic temperature elevation.

Thermosensitive magnetic micro- or nanogels are typically made of thermosensitive, hydrophilic and functional polymers, which can be physically or chemically crosslinked to form a gel network and presenting a volume phase transition temperature (VPTT) or a LCST. The local temperature can generate the swelling-deswelling transition of the nanogels, thus remotely trigger drug release.

Among these functional polymers, Poly(N-isopropylacrylamide) (PNIPAm) is considered a gold standard material for preparing thermoresponsive nanodevices. Despite its low LCST $\left(32{ }^{\circ} \mathrm{C}\right)$ the temperature can be easily tuned above $37^{\circ} \mathrm{C}$ by simply copolymerizing NIPAm with more hydrophilic monomers.

Magnetic micro or nanogels can be classified according to the nature of the interaction between the MNPs and the polymer chains (covalent or hydrogen bonds), the morphology of the gel (core or core@shell) and the distribution of MNPs within the polymer matrix (inside or at the surface of the matrix). For their synthesis, MNPs can be introduced before or after the polymerization step; or can be synthesized in situ in the nanogels' matrix.

Kondo et al. synthesized magnetic nanogels of PNIPAm by adding $\mathrm{Fe}_{3} \mathrm{O}_{4} \mathrm{NPs}$ before the polymerization process. To allow the dispersion of the $\mathrm{Fe}_{3} \mathrm{O}_{4}$ NPs, the authors synthesized a polystyrene shell (PS) around the NPs. This shell also allows to interact with growing PNIPAm chains and to aid polymerization around the MNPs [28]. Nevertheless, it is neither possible to control the diameter of the nanogels (100 to $400 \mathrm{~nm}$ ), nor the quantity of incorporated MNPs (5-20\% by mass) using this method $[28,29]$. Recently, the effect of NPs stabilization on the synthesis of $\mathrm{Fe}_{3} \mathrm{O}_{4} /$ PNIPAm hybrid nanogels has been studied by Jaiswal et al. [30]. In this study, different ligands (citric acid, ethylene diamine, chitosan) were used. The authors showed that the mass ratio in NPs (\%) inside the nanogels is increased, up to $40 \%$, by stabilizing MNPs in the solution during the polymerization reaction. Using this method, it is possible to develop hybrid nanogels in a single step. However, it is very difficult to control the physico-chemical properties of nanogels (size, polydispersity, distribution of NPs within the polymer matrix), as well as the amount of MNPs incorporated into the matrix. In addition, the polymerization of the monomers in the presence of MNPs tends to form a core-shell structure, with a core containing mainly MNPs and a shell composed essentially of polymer.

Otherwise, Kumacheva et al. synthesized $\mathrm{pH}$ - and thermosensitive hybrid PNIPAm nanogels functionalized with acrylic acid (AA), by forming in situ the iron oxide NPs in the polymer matrix [31]. In the same way, Kawaguchi et al. used functionalized PNIPAm nanogels with glycidyl methacrylate (GMA) groups, to prepare the MNPs inside the polymer matrix [32-34]. The incorporation of GMA groups is very interesting because these groups can be modified after polymerization to introduce various active functions, such as amine, carboxylate and sulfonate, by post-modification with thiol compounds.

Furthermore, the synthesis of magnetic nanogels can be carried out by a post-synthesis assembly of thermosensitive nanogels and inorganic MNPs. The constituents (nanogels and MNPs) are synthesized separately before being assembled by electrostatic interactions, by formation of complexes or by covalent bonds between nanogels and MNPs. In this way, Pichot et al. prepared negatively charged MNPs coated with sodium citrate and positively charged nanogels functionalized with amine groups $[35,36]$. The assembly of these objects takes place at $\mathrm{pH}$ 7.0, however if the $\mathrm{pH}$ is modified, the desorption of NPs is observed. One advantage of post-assembly process is that it allows the tuning of the magnetic and thermoresponsive properties of individual components (nanoparticles and microgels) separately before assembling them.

Huge efforts were dedicated to the synthesis of these magneticthermoresponsive polymers platforms. However their heat responsiveness was often tested by using a water bath rather than AMF.

\subsubsection{Drug delivery under AMF}

PNIPAm magnetic microgels were prepared by R. Regmi et al. by adding $\mathrm{Fe}_{3} \mathrm{O}_{4}$ nanoparticles inside the polymeric matrix after the radical polymerization of microgels [37]. These nanogels have a LCST around $38{ }^{\circ} \mathrm{C}$ and show substantial heating, reaching $50{ }^{\circ} \mathrm{C}$ in only $4 \mathrm{~min}$, and releasing $1 \%$ of the drug (mitoxantrone) per minute, when exposed to an AMF (380 kHz; $\left.10.3 \mathrm{kA} \cdot \mathrm{m}^{-1}\right)$.

M. Jaiswal and co-workers also prepared PNIPAm magnetic nanogels, but $\mathrm{Fe}_{3} \mathrm{O}_{4}$ nanoparticles were entrapped in the polymer matrix during the polymerization process [38]. These nanogels (hydrodynamic diameter $200 \mathrm{~nm}$ ) have a LCST of $40{ }^{\circ} \mathrm{C}$ and are able to induce a two-fold increase of the drug release (doxorubicin) under AMF $(5 \mathrm{~kW}, 230 \mathrm{kHz}, 1 \mathrm{~h})$ without macroscopic heating. These nanogels induced a cell death of $80 \%$ after 1 h of AMF (HeLa cells). J. Wong and co-workers prepared microgels by a layer-by-layer assembly of polyelectrolytes (adding successively positively charged poly (diallyldimethylammonium chloride) (PDADMAC) and negatively charged poly(acrylic acid) in order to facilitate the deposition of 
MNPs at the surface of PNIPAm nanogels [39]. The as prepared nanogels $\left(\mathrm{d}_{\mathrm{h}}=190 \mathrm{~nm}, \mathrm{LCST}\right.$ around $\left.32^{\circ} \mathrm{C}\right)$ are able to heat above $50{ }^{\circ} \mathrm{C}$ in $<30 \mathrm{~s}$ when applying an AMF ( $\left.360 \mathrm{kHz}, 20 \mathrm{kA} \cdot \mathrm{m}^{-1}\right)$. Thus, the magnetic shell generates enough heat to provoke the deswelling of the PNIPAm core.

Although the NIPAm monomer is highly cytotoxic, it has been shown in the literature that the cytotoxicity of the PNIPAm polymer is less or even zero. However, after several purification steps, the PNIPAm crosslinked matrices may still contain monomers, making the system toxic $[40,41]$. In addition, PNIPAm can also interact with human body proteins due to the presence of several amide functions in its chemical structure [42]. Thus, it is very difficult to use this polymer for biomedical applications. Otherwise, some natural polymers, such as alginate, have also been used for designing biocompatible magnetic microgels. C. Ménager et al. [43] prepared magnetic alginate microbeads by microemulsion polymerization and loaded with doxorubicin (DOX) and $\gamma-\mathrm{Fe}_{2} \mathrm{O}_{3}$ NPs. DOX released was enhanced from these nanogels, from $25.9 \mu \mathrm{g} \cdot \mathrm{mL}^{-1}$ (water bath at $37{ }^{\circ} \mathrm{C}$ ) to $60 \mu \mathrm{g} \cdot \mathrm{mL}^{-1}$, by applying an $\operatorname{AMF}(700 \mathrm{kHz}, 26 \mathrm{mT}, 2 \mathrm{~h})$.

Recently, magnetic nanogels based on biocompatible, water-soluble and non-toxic monomers derived from oligo (ethylene glycol methyl ether methacrylate) monomers (OEGMAs) have been synthesized [44-46]. Cazares-Cortes et al. synthesized pH and thermoresponsive OEGMAs-nanogels by conventional precipitation radical copolymerization in water and post-assembled by complexation with $\gamma-\mathrm{Fe}_{2} \mathrm{O}_{3} \mathrm{NPs}$ [47]. This method provides monodisperse nanogels with a high content of homogeneously distributed magnetic nanoparticles. The mass ratio of loaded MNPs inside nanogels can be tuned from 9.0 to $37.5 \mathrm{wt} \%$ (Fig. 3a). Biocompatible nanogels (hydrodynamic diameter from 328 to $460 \mathrm{~nm}$, LCST $=47{ }^{\circ} \mathrm{C}$ at pH 7.5), containing $37.5 \mathrm{wt} \%$ MNPs, have a high drug loading efficiency (63\%). The release of doxorubicin (DOX) from the nanogels can reach $47 \%$ at pH 7.5 under AMF (24\% without AMF) in athermal conditions. Here, magnetic nanoparticles act as individual nanoheaters or "hot-spots". They generate a localized heating, without raising the global temperature of the media. The heat is enough to provoke the phase transition of the polymers chains. Interestingly, it was demonstrated that these nanogels are excellent nanocarriers for enhancing the internalization of DOX inside PC-3 cancer cells and that it is possible to trigger intracellularly and remotely DOX release under AMF (335 kHz, 12 A.m ${ }^{-1}$ ), thus enhancing DOX efficiency in terms of cytotoxicity. Cancer cell viability was reduced from 51 to $32 \%$ in the presence of DOX-nanogels and (DOX-nanogels +AMF), respectively (Fig. 3b).

Multi-responsive nanogels, combining two or more stimuli, are useful for treating diseases characterized by the variation of an internal parameter (temperature, $\mathrm{pH}$, redox composition). For example, anticancer therapies must be improved by using nanocarriers sensitive to both acidic media and AMF. Indeed, the $\mathrm{pH}$ variation between the physiological environment of normal cells ( $\mathrm{pH} 7.5$ ) and cancer cells ( $\mathrm{pH}$ 4.5-6.5) would enhance drug release inside cancer cells [48-50]. In addition, using an AMF as external stimulus may provide regulation of the amount of drug released, enhancement of the therapeutic effectiveness and decrease of systemic toxicity, notably through spatial and temporal control of drug release.

\subsubsection{In vivo drug release under $A M F$}

Despite the large portfolio of thermoresponsive nanosystems tested in vitro, only few studies have demonstrated the efficacy of AMF for in vivo drug release. [51,52]

Injectable hydrogel that undergoes a gelation process at $37^{\circ} \mathrm{C}$, keeping the MNPs at the tumor site and causing a heat mediated release of encapsulated necrotic factors was developed. MNP were also clustered inside a poly(pyrrole carboxylic acid) exhibiting a glass transition at $44{ }^{\circ} \mathrm{C}$ and loaded with DOX. The material injected intratumorally was able to cause complete tumor suppression due to the dual MHT heat $\left(44{ }^{\circ} \mathrm{C}\right)$ and chemotherapeutic effect [53].

Efficient drug releasing magnetic polymeric NPs for anti-epileptic applications, based on thermosensitive PEO-PPO-PEO(F127) triblock copolymer nanogels bound with PVA and loaded both with magnetic NPs and ethosuximide (ETX), a calcium channel blocker for antiepilepsy applications were recently developed [54]. After intravenous injection and magnetic targeting of the NPs toward the rat brain, the reduction of epileptic episodes measured by electrophysiological recording was demonstrated through the decrease of the spike-wave discharges (SWD) over $2 \mathrm{~h}$, upon the AMF-induced $\left(2.5 \mathrm{kAm}^{-1}\right.$, $44.2 \mathrm{kHz}, 15 \mathrm{~s}$ ) burst release of ETX (Groupe I) whereas free ETX administered ( $1 \mathrm{~h}$, Groupe III) or ETX-loaded PVA (Groupe II) nanogels were shown not efficient (Fig. 4a).

Injectable, biodegradable and thermosensitive TRAIL/SPION (tumor necrosis factor-related apoptosis-inducing ligand/superparamagnetic iron oxide nanoparticle) nanocomplex hydrogels (T/S-NH) were used
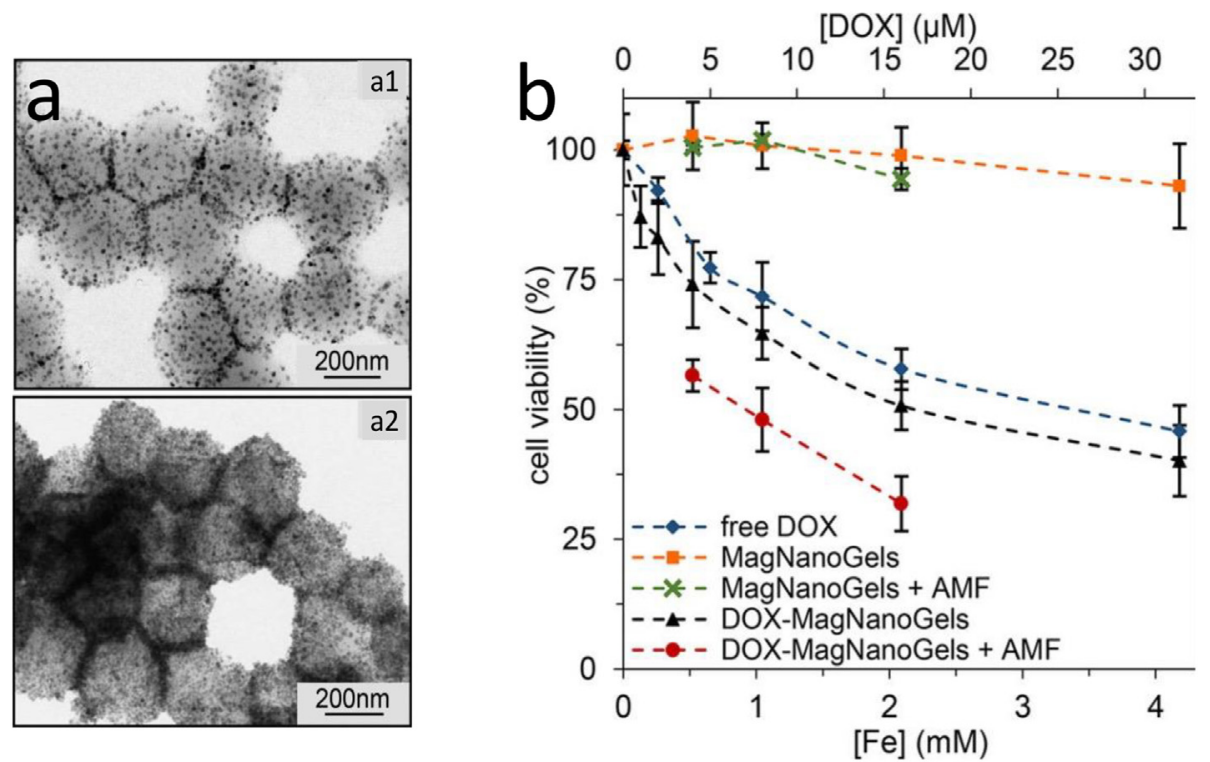

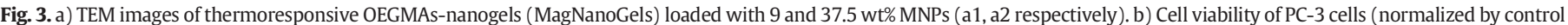

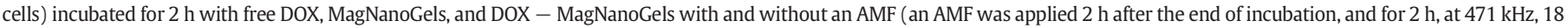

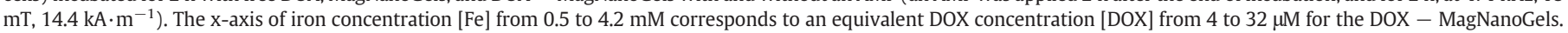
Reproduced with permission from ref. [47]. Copyright 2017 the American Chemical Society. 
a

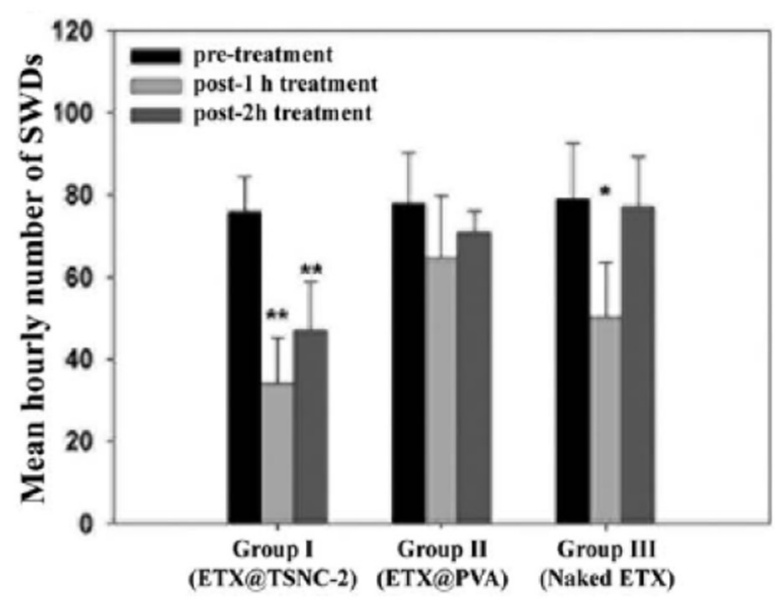

b

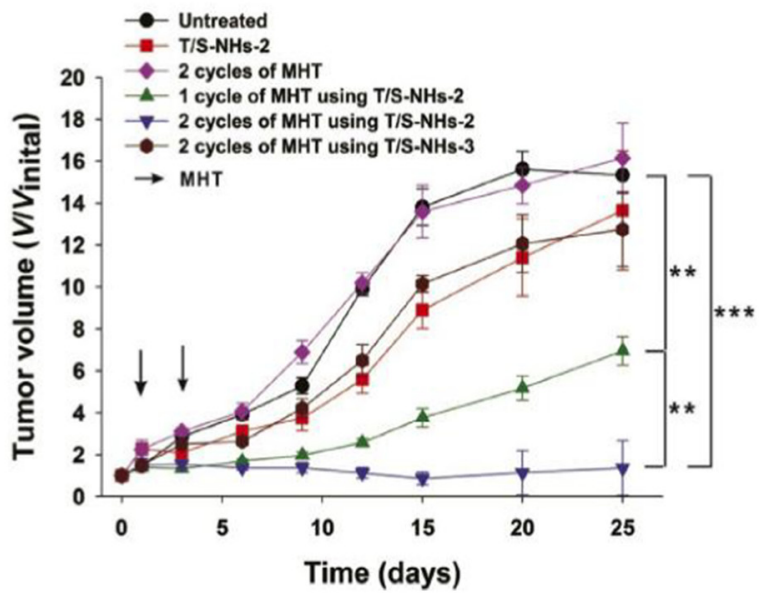

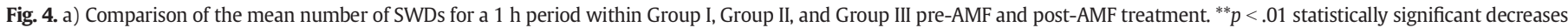

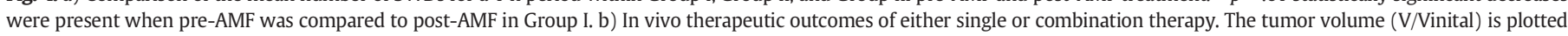
versus time after treatment. The arrow indicates the day of MHT. The symbol ** indicates the statistical significance at levels of $P<.01$ and $* * *$ indicates $P<.001$.

in combination with mild multiple MHT and MHT-mediated TRAIL release, with the aim of killing TRAIL-resistant glioblastoma multiforme cells [55]. Hyperthermia can enhance the release of TRAIL from hydrogels through temperature-sensitive hydrogel dissolution. TRAILresistant U-87 MG cells were killed by the combination of TRAIL and multiple hyperthermia via caspase- 3 and -8 active apoptosis. The hyperthermia enhanced cytotoxicity of TRAIL was dependent on the hyperthermia cycle number and corresponding TRAIL release. Significant in vivo tumor reduction was observed by combining 2 cycles of mild MHT and TRAIL release using a single injection of TRAIL/SPION nanocomplex hydrogels without damage to main organs (Fig. 4b).

\subsection{Molecularly imprinted polymer}

When molecularly imprinted polymers (MIPs), a templating process at the molecular level, were first described several decades ago [56-58], they were mostly used as separation materials in analytical chemistry. MIPs are prepared in presence of a template that serves as a mold for the formation of template complementary binding sites. The resulting molecularly imprinted polymers are being used in a wide range of applications, such as chiral separation [58,59], chemical sensing [60,61], competitive drug assays [62], chemical catalysis [63], or solid phase extraction $[64,65]$. MIP synthesis is reproducible, fast and economic. They are physically and chemically very stable, they are not easily degraded by proteases or denatured by solvents, and they can be engineered and tailored for a given application. In principle, MIP can be obtained for any target, even when no natural receptor or antibody exists.

Furthermore, the advantage of such a system is the possibility to integrate a drug inside the polymer and regulate the drug release by increasing the residence time of the therapeutic agent within the polymeric matrix, by means of either covalent or non-covalent interactions in specific binding sites. In this context, a new potential application of MIP in controlled drug release has attracted considerable attention [66-70]. Although imprinted drug delivery systems have not reached clinical application yet, this technology has an enormous potential for creating satisfactory dosage forms. Several works have been reported to prepare MIPs with different morphologies as delivery carriers to control release of drugs, such as monoliths, granules, membranes and microspheres [71-74]. However, the best shape of MIPs may be the spherical one due to their excellent isotropic release capacity [75]. Since the surface area per unit volume of a material is inversely proportional to the size of the material, nanosize MIPs have enormous binding capacity. The small size of nanoparticles also enables those materials to be considered for therapeutic applications such as injection into the blood stream of living animals. In 2010, K. Shea et al. proposed molecular imprints in polymer nanoparticles for the toxic peptide melittin, the main component of bee venom. They created artificial antibodies that can be used for the in vivo capture and neutralization of melittin [76]. They showed that polymer particles are compatible with the aqueous environment in living organisms, have readily accessible binding sites for the target, and are able, like real antibodies, to neutralize its toxic effect.

It is only recently that novel stimuli such as UV illumination or AMF were employed for drug release from MIP. For example, asymmetric MIP particles (Janus particles) synthesized via a wax-water Pickering emulsion were suggested as self-propelled transporters for controlled drug delivery [77]. Release of the drug from the Janus MIP particles can be controlled by switching on-off the UV illumination. But this system lacks biocompatibility due to the use of Ag NPs and the limitation of UV illumination which damages cells. Therefore, there is a demand of adjustment for practical applications.

Concerning the magnetic MIPs, they have emerged as powerful materials for controlled drug delivery systems because they can be localized to the pre-delivery sites and release the drug to particular sites by the external magnetic field [78]. Hence, nanospherical magnetic MIPs should be suitable as an ideal polymer material for wider applications. Nonetheless, few studies have been reported on the preparation of nanospherical magnetic MIPs $[79,80]$ and only five studies have been reported about the controlled release of drugs by nanospherical magnetic MIPs. It is only in 2015 that Griffete et al. [81] developed an innovative magnetic delivery nanomaterial for triggered cancer therapy showing active control over drug release by using an alternative magnetic field. The material, which combines the controlled drug release ability of non-thermosensitive MIPs with magnetic properties of iron oxide, allows the controlled release of doxorubicin. Upon AMF exposure, the hydrogen bonds between the MIP and the DOX are broken and the molecule is released without any significant heating of the medium. This strategy is efficient for in cells experiments (Fig. 5). These nanomaterials offer great promise for the doxorubicin release under a magnetic field and moreover we think that this approach will be easily expanded to other polymers, targeting molecules or drugs. The use of MIP for drug delivery under an alternative magnetic field is a major advance in the development of multifunctional targeted drug delivery nanotechnologies and may become an important theranostic tool in nanomedicine. 

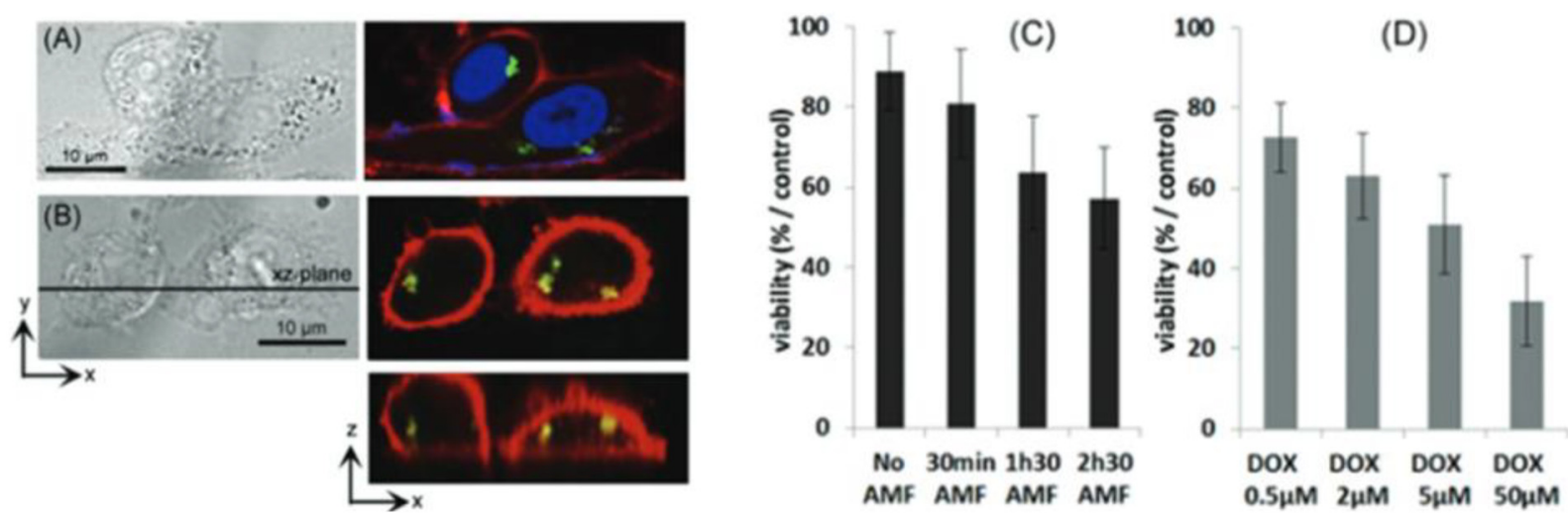

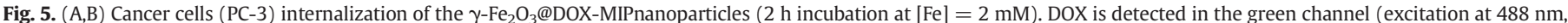

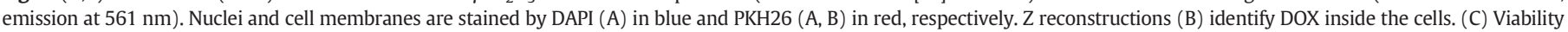

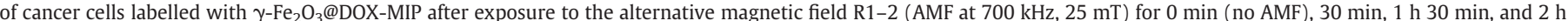

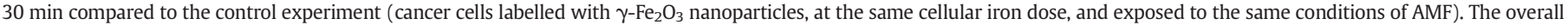

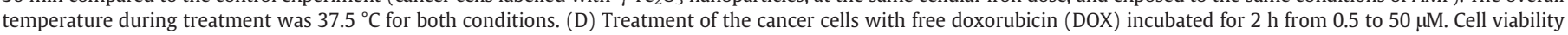

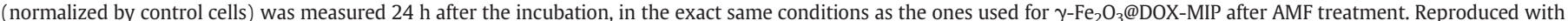
permission from ref. [81]. Copyright 2015 Royal Society of Chemistry.

The list of reports dealing with the elaboration of magnetic and polymeric nanosystems for drug release under an AMF are summarized in Table 1.

\section{Increasing the heat delivered per nanoparticles}

As discussed previously, compared to other physical stimuli, MHT is an attractive physical modality for biomedical applications such as drug delivery and thermal therapy. However, despite such advantages, MHT is still facing some limitations related to the fact that the used superparamagnetic MNPs suffer from relatively low heat-generating efficiency. Given the limit of allowed magnetic field strength for living organs and the injectable dosage of MNPs there is a strong need for the development of NPs with optimized heating efficiency to achieve the necessary application. The most investigated strategy is based on modulation of the design of the MNPs to improve heat generation. In such direction several groups reported on the synthesis of MNPs where the magnetization and/or the anisotropy and/or the size have been modulated to enhance the Specific Absorption Rate (SAR). Comprehensive reviews on the recent advances for magneto-thermal capabilities of nanoparticles dealing with design principles and biomedical applications have been recently published [85-88]. Another engineering alternative is based on the design of nanocombined inorganic based therapies including several components which can be physically and remotely stimulated and can develop synergistic properties. Magnetoplasmonic nanoplatforms combining the advantages of MHT and PTT are one of the most recent strategies and will be developed in this section.

\subsection{Magnetoplasmonic NPS}

If MNPs are the best candidate for applications in hyperthermia, the last 20 years have witnessed an increase in the number of publications showing the efficiency of plasmonic materials as powerful thermal

Table 1

Magnetic and polymeric nanosystems for drug release under an alternative magnetic field (AMF).

\begin{tabular}{|c|c|c|c|c|c|c|c|}
\hline Nanostructure type & Components $^{\mathrm{a}}$ & Bio conditions & AMF Modality & $\Delta \mathrm{T}$ & $\begin{array}{l}\text { Drug } \\
\text { encapsulation }^{\mathrm{a}}\end{array}$ & Drug release & Reference \\
\hline $\begin{array}{l}\text { Core@shell } \\
\text { magnetic nanocubes coated } \\
\text { with polymer } \\
(200 \mathrm{~nm})\end{array}$ & $\begin{array}{l}\gamma-\mathrm{Fe}_{2} \mathrm{O}_{3}(20 \mathrm{~nm}) \\
\text { PNIPAM-Co-PEGMA }\end{array}$ & - & 220 kHz; 20 k.A.m ${ }^{-1}$ & $\begin{array}{l}25 \text { to } 80{ }^{\circ} \mathrm{C} \text { in } \\
15 \mathrm{~min}\end{array}$ & $\begin{array}{l}\text { DOX } \\
0.67 \mathrm{~g} / \mathrm{g} \mathrm{Fe}\end{array}$ & $\begin{array}{l}310^{-1} \mathrm{mg} / \mathrm{mL} \\
(4 \mathrm{~h}) \\
\text { at } 80^{\circ} \mathrm{C}\end{array}$ & {$[82]$} \\
\hline $\begin{array}{l}\text { core@shell microgels } \\
(190 \mathrm{~nm})\end{array}$ & $\begin{array}{l}\mathrm{Fe}_{3} \mathrm{O}_{4} \\
\text { PNIPAM + layer-by-layer } \\
\text { PDADMAC and PAA }\end{array}$ & - & $\begin{array}{l}\text { AMF } \\
360 \mathrm{kHz}, 20 \mathrm{kA} \cdot \mathrm{m}^{-1}\end{array}$ & $\begin{array}{l}>50^{\circ} \mathrm{C} \text { in less } \\
\text { than } 30 \mathrm{~s}\end{array}$ & - & - & [39] \\
\hline $\begin{array}{l}\text { Magnetic nanogels } \\
(250-450 \mathrm{~nm})\end{array}$ & $\begin{array}{l}\gamma-\mathrm{Fe}_{2} \mathrm{O}_{3}(11.5 \mathrm{~nm}) \\
\mathrm{P}(\text { OEGMAs-co-MAA })\end{array}$ & In vitro $\mathrm{PC}-3$ cells & $\begin{array}{l}335 \mathrm{kHz} ; 12 \mathrm{~A} \cdot \mathrm{m}^{-1} \text {, } \\
(4 \times 30 \mathrm{~min})\end{array}$ & $\begin{array}{l}37{ }^{\circ} \mathrm{C} \\
\text { athermal } \\
\text { conditions }\end{array}$ & $\begin{array}{l}\text { DOX } \\
15 \mathrm{mg} / \mathrm{g} \\
\text { carrier }\end{array}$ & $100 \%$ at $\mathrm{pH} 5$ & [83] \\
\hline Magnetic nanogels (200 nm) & $\begin{array}{l}\mathrm{Fe}_{3} \mathrm{O}_{4}(12 \mathrm{~nm}) \\
\text { PNIPAM }\end{array}$ & In vitro HeLa cells & $\begin{array}{l}230 \mathrm{kHz} ; 30 \mathrm{kA} \cdot \mathrm{m}^{-1} \text {; } \\
1 \mathrm{~h}\end{array}$ & $40{ }^{\circ} \mathrm{C}$ & $\begin{array}{l}\text { DOX } \\
6 \mu \mathrm{g} / \mathrm{mg} \\
\text { carrier }\end{array}$ & $\begin{array}{l}8,4 \cdot 10^{-3} \\
\mathrm{mg} / \mathrm{mL}\end{array}$ & [79] \\
\hline Magnetic MIPs (57 nm) & Poly(acrylamide-co-acrylic acid) & In vitro $\mathrm{PC}-3$ cells & A $700 \mathrm{kHz} ; 25 \mathrm{mT}$ & $\begin{array}{l}37^{\circ} \mathrm{C} \\
\text { Athermal } \\
\text { conditions }\end{array}$ & $\begin{array}{l}\mathrm{DOX} \\
6,5 \mu \mathrm{g} / \mathrm{mL}\end{array}$ & $\begin{array}{l}3,26.10^{-3} \\
\mathrm{mg} / \mathrm{mL}\end{array}$ & [13] \\
\hline Magnetic microgels & $\begin{array}{l}\mathrm{Fe}_{3} \mathrm{O}_{4} \\
\text { PNIPAM }\end{array}$ & - & 380 kHz;10.3 kA.m ${ }^{-1}$ & $50{ }^{\circ} \mathrm{C}$ in $4 \mathrm{~min}$ & $\begin{array}{l}\text { Mitoxantrone } \\
\text { (not } \\
\text { indicated) }\end{array}$ & $1 \%$ of drug $/ \mathrm{min}$ & [37] \\
\hline $\begin{array}{l}\text { Nanocomplexe hydrogels } \\
\qquad(400 \mathrm{~nm})\end{array}$ & $\begin{array}{l}\mathrm{Zn}_{0.47} \mathrm{Mn}_{0.53} \mathrm{Fe}_{2} \mathrm{O}_{4}(18 \mathrm{~nm}) \\
\mathrm{PZC}\end{array}$ & $\begin{array}{l}\text { In vivo } B A L B / c \\
\text { nude mice }\end{array}$ & $\begin{array}{l}366 \mathrm{kHz} ; 13.3 \mathrm{kA} \cdot \mathrm{m}^{-1} \\
(2 \times 60 \mathrm{~min})\end{array}$ & $43^{\circ} \mathrm{C}$ & $\begin{array}{l}\text { TRAIL } \\
20 \mu \mathrm{g} / \mathrm{g} \\
\text { sample }\end{array}$ & $\begin{array}{l}80 \% \text { release in } \\
20 \text { days }\end{array}$ & {$[84]$} \\
\hline
\end{tabular}

a PNIPAM: poly(N-isopropylacrylamide)/PDADMAC: poly(diallyldimethylammonium chloride)/PAA: poly(acrylic acid)/PEGMA: co-polyethylene glycolmethyl ether acrylate /

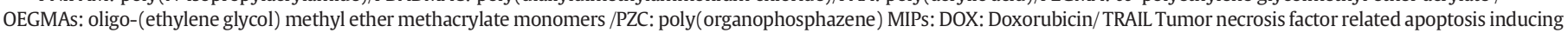
ligand (TRAIL). 
agents for applications in cancer therapy and drug delivery. Plasmonic nanoparticles such as gold $(\mathrm{Au})$ and silver $(\mathrm{Ag})$, have fascinating physical, chemical and optical properties resulting from the spatial confinement of the electrons at the nano-scale. When the wavelength of an incoming light applied on the surface of metallic nanoparticles is much larger than the nanoparticle size, its electron cloud will resonate. The electrons of the nanoparticle will collectively oscillate in the conduction band in resonance with the light's frequency [89] . As a result, the electron cloud is displaced relative to the nuclei, so the surface remains charged positively where the cloud is lacking electrons and negatively where they are concentrated [90] (Fig. 6). This collective oscillation of all the electrons is called plasmon band, in contrast to bulk materials, where electrons are not allowed to travel through the material [91]. The excitation phenomenon on the metal nanoparticle surface is called localized surface plasmon resonance (LSPR).

The LSPR has two main characteristics: an enhancement of the electric field near the particles' surface (which is higher at the surface and become lower with distance) and a maximum optical extinction at the plasmon resonance frequency [92]. The shape, the size and the surrounding medium [93-97] are all parameters that can affect the LSPR. Consequently the synthesis of plasmonic materials can be modulated to obtain optical responses in the near infrared window where light scattering effects are minimized by tissues, thus suitable for biomedical applications [98-101]. Among plasmonic materials Au nanoparticles are the most used and reported probably because of their high biocompatibility, chemical stability and the rich surface chemistry of Au which make them powerful nanoplatforms for biomedical applications. Consequently, this section of the review will first focus on gold based magnetoplasmonics. For applications in the biomedical field, numerous morphologies with suitable LSPR have been elaborated including gold nanorods [102], truncated octahedral [103], nano-pearl necklaces [104], nanostars [105], nanoeggs [106], nanoflowers [107]. Their optical properties allowed their applications as biosensors, contrast agents or in surface enhanced Raman spectroscopy [108-112]. Moreover due to their high total extinction coefficients and their capacity to convert into heat the strong absorption of light, gold nanoparticles are more efficient in photothermia than magnetic particles in MHT, and largely used for applications in cancer therapy or in drug delivery [113-115]. Besides, gold nanoparticles could overcome some of the challenges faced by MHT, including the low heat yield generated/ MNP and the low chemical stability of iron oxides in the intracellular environment [116]. However, MHT still offers numerous advantages such as no depth limitations in tissues, magnetic manipulation and targeting. Combining both materials into one single nanohybrid through the elaboration of optimized multifunctional magnetoplasmonic nanoplatforms may allow not only to inherit from the two components excellent surface chemistry, special optical properties, and superparamagnetic properties but also to hurdle some limitations of MHT through the development of synergies resulting from their association.

\subsubsection{Synthesis of magnetoplasmonic nanohybrids}

To design such magnetoplasmonic multicomponent hybrid nanoparticles, self-assembly or molecular bottom up approaches can be used and their synthesis have been very recently reviewed elsewhere [117]. The resulting nanohybrids can be summarized into three main designs (Fig. 7): particles embedded into a biocompatible polymer or silica compartment, core/shell materials, or heterodimeric structures $[109,118]$, which both can be obtained through the seed growth strategy.

Among such structures, the magnetoplasmonic core@shell ones are the most widely reported morphologies in the literature. This is because core/shell structures are easily tunable as their size and shape can be tailored to reach higher control over their optical and physical properties. The shell layer protects the core from oxidation and enhance stability and biocompatibility $[109,126]$ but also permits further surface functionalization [127-129]. Depending on the structure of the coating layer, core/satellite nanoparticles, characterized by a single core with the attachment of numerous smaller nanoparticles can be distinguished from core/shell nanoparticles, which possess fully covered surface due to shell coating $[109,130]$. Focusing on the synthesis of this type of nanoparticles, different chemical and physical approaches have been proposed to prepare them. However, the most used one is the chemical deposition process, which consists in the direct deposition of seeds on already prepared cores followed by a controlled growth of the seeds to form a more or less continuous coating around them [118]. Referring to the nature of the core, two types of magnetoplasmonic nanoparticles can be distinguished: those with a single or multiple magnetic core, mainly magnetite or maghemite which have been deeply investigated and successfully synthesized, and nanoparticles having a plasmonic core, usually formed by silver or gold metals [109,118]. Incorporating the plasmonic component inside the magnetic shell represents a synthetic challenge as the difference in the surface energies could give rise to the segregation of the plasmonic and magnetic component [131]. Moreover the optical and physical properties of the plasmonic part can be inactivated in such structure $[132,133]$.

\subsubsection{Magnetoplasmonic $\mathrm{Fe}_{3} \mathrm{O}_{4} @ a u$ for thermal therapies}

Concerning the applications of magnetoplasmonic nanohybrids as nanothermal agents, although different architectures have been reported (Table 2) surprisingly and in majority only the plasmonic part has been investigated for hyperthermia applications. The iron oxide component has been mainly used as a MRI agent or for magnetic manipulation and targeting [128,134-137]. Fan et al. [138] developed S6 aptamer-conjugated magnetic core plasmonic shell nanoparticles for the targeted diagnosis, isolation, and photothermal destruction of SK-BR-3 human cancer cells. During the photothermal destruction of SK-BR-3 cancerous cells bound to S6 aptamer-conjugated magnetic/ plasmonic nanoparticles, the localized heating that occurs due to the absorption of $670 \mathrm{~nm}$ continuous NIR irradiation is able to cause irreparable cellular damage; it selectively kills most of the cancerous cells within $10 \mathrm{~min}$ at $2.5 \mathrm{~W} / \mathrm{cm}^{2}$. Very recently Li et al. [139] developed a kind of bioeliminable magnetoplasmonic nanoassembly for photothermal cancer therapy under the guidance of trimodal imaging of computer tomography (CT), photoacoustic tomography (PAT) and MRI. A single dose of photothermal therapy under near-infrared light induced a complete tumor regression in mice. The idea of designing

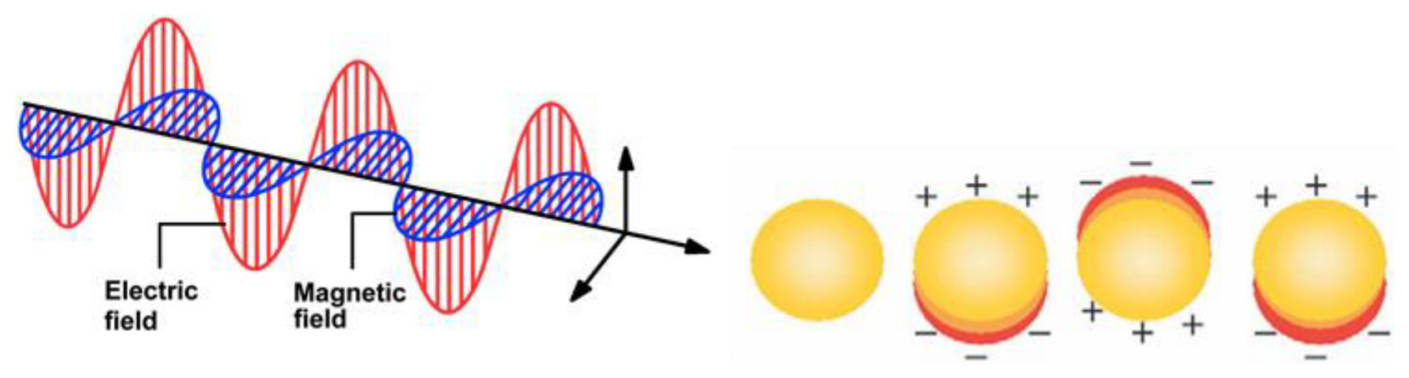

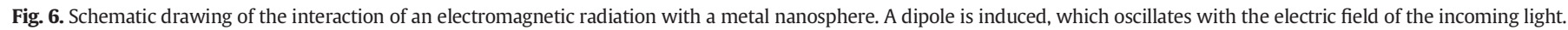


I
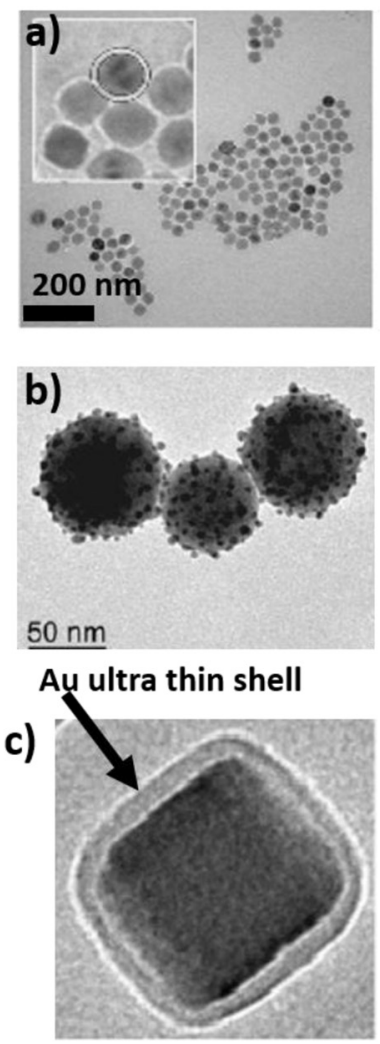

II

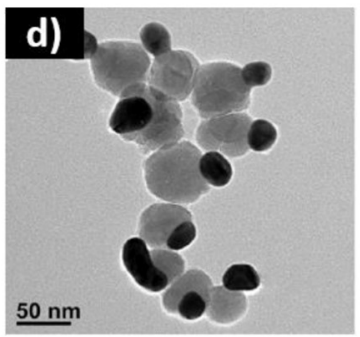

e)

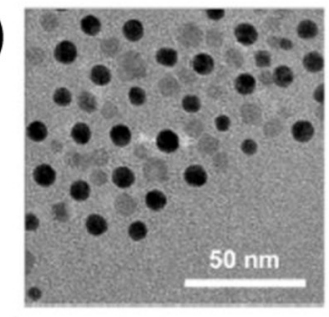

f)

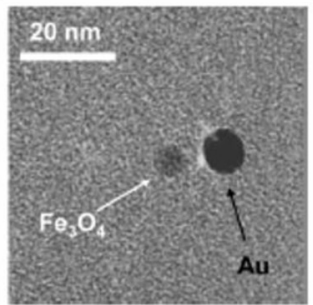

III
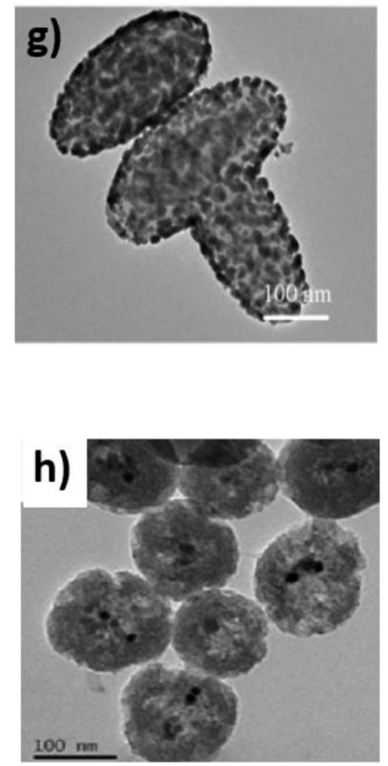

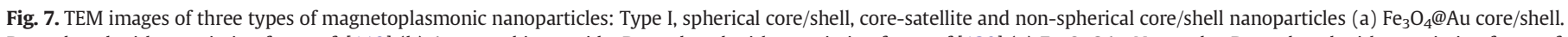

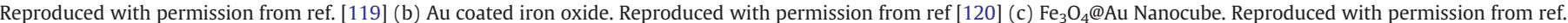

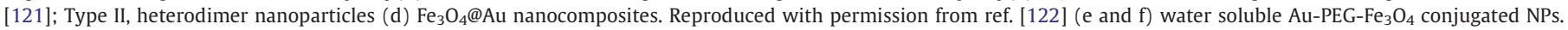

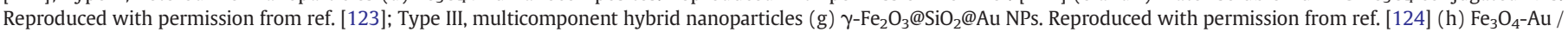
$\mathrm{pSiO}_{2}$ core/shell NPs. Reproduced with permission from ref. [125].

optimized magnetoplasmonic nanoplatforms for applications in combined bimodal magnetic hyperthermia and plasmonic photothermia is very recent. In 2013 Abdulla-Al-Mamun and collaborators proposed core@shell nanostructures formed by magnetic nanocubes and a gold ultrathin layer for hyperthermia-photothermal activity. [121] The magnetic core of the nanoheaters was prepared by a colloidal method and the gold shell was synthesized by seed growth. It was demonstrated under the simultaneously combined magnetic field and photoirradiation with $\mathrm{Fe}_{3} \mathrm{O}_{4} @ \mathrm{Au}$ a much higher HeLa cells killing than when both external stimuli are applied separately (Fig. 8.I).

In 2015 an optimized magnetoplasmonic core/shell structure associating a magnetic nanoflower core optimized for MHT and a multibranched gold shell optimized for photothermia was designed by our group [139]. Once again, the aim is to overcome the limitations of magnetic hyperthemia by photothermia while allowing magnetic manipulation and targeting. The versatility of the system in generating heat through a remarkable cumulative effect when both magnetic and plasmonic modalities were applied simultaneously was demonstrated and showed for the first time that the heating efficiency was maintained under in vivo conditions. The tumor temperature can then rapidly reach $48{ }^{\circ} \mathrm{C}$, a condition for therapeutic tumor ablation, with a dose injected 10 times lower than that for classical MHT treatment (Fig. 8. II). Besides, such core/shell structure brings the additional advantage of providing the hybrid with a biostability overcoming the one of MNPs alone, and thus maintaining the thermal efficiency on the longterm, in the intracellular environment [141]. More recently Lu et al.

Table 2

Magnetoplasmonic MNP@Au nanostructures and their applications in PTT and combined MHT + PTT.

\begin{tabular}{|c|c|c|c|c|c|}
\hline Nanostructure type & Components & Bio conditions & Modality & $\Delta \mathrm{T}$ & Reference \\
\hline Multicore@shell & $\mathrm{Fe}_{3} \mathrm{O}_{4} \& \mathrm{Au}$ & $\begin{array}{l}\text { HepG2 cells } \\
\text { In vivo }\end{array}$ & Mono & $808 \mathrm{~nm} 0.7$ and $1 \mathrm{~W} / \mathrm{cm}^{2} 10 \mathrm{~min} \rightarrow 37^{\circ} \mathrm{C}$ & {$[139]$} \\
\hline Core@core@shell & $\mathrm{Fe}_{3} \mathrm{O}_{4} \& \mathrm{SiO}_{2} \& \mathrm{Au}$ & HepG2 cells & Mono & $808 \mathrm{~nm} 2 \mathrm{~W} / \mathrm{cm}^{2} 10 \mathrm{~min} \rightarrow 40{ }^{\circ} \mathrm{C}$ & [137] \\
\hline Multicore@shell & $\mathrm{Fe}_{3} \mathrm{O}_{4} \& \mathrm{Au}$ & PC3 cells & Mono & $680 \mathrm{~nm} 0.3 \mathrm{~W} / \mathrm{cm}^{2} \rightarrow 10-12^{\circ} \mathrm{C}$ & [143] \\
\hline Dumbbell like & $\mathrm{Fe}_{3} \mathrm{O}_{4} \& \mathrm{Au}$ & SW1222 colorectal cells & Mono & $808 \mathrm{~nm} 5 \mathrm{~W} / \mathrm{cm}^{2} 10 \mathrm{~min} \rightarrow 29^{\circ} \mathrm{C}$ & {$[144]$} \\
\hline Core@shell & $\mathrm{Fe}_{3} \mathrm{O}_{4} \& \mathrm{Au} \& \mathrm{SiO}_{2}$ & SKBR3 cells & Mono & $808 \mathrm{~nm} 3.72 \mathrm{~W} / \mathrm{cm}^{2} 10 \mathrm{~min} \rightarrow$ live/dead stain & {$[145]$} \\
\hline Core@shell & $\begin{array}{l}\mathrm{Fe}_{3} \mathrm{O}_{4} @ \mathrm{P}(\mathrm{St} / \mathrm{MAA}) @ \\
\text { Chitosan@Au }\end{array}$ & $\begin{array}{l}\text { L929 cells } \\
\text { HepG2 cells }\end{array}$ & Mono & $808 \mathrm{~nm} 1 \mathrm{~W} / \mathrm{cm}^{2} 10 \mathrm{~min} \rightarrow$ cell viability assays & [146] \\
\hline Core@shell & $\mathrm{Fe}_{3} \mathrm{O}_{4} \& \mathrm{Au} \& \mathrm{~S} 6$ & SK-BR-3 cells & Mono & $670 \mathrm{~nm} 2.5 \mathrm{~W} / \mathrm{cm}^{2} 20 \mathrm{~min} \rightarrow$ up to $55^{\circ} \mathrm{C}$ & {$[140]$} \\
\hline Core@shell & $\mathrm{Fe}_{3} \mathrm{O}_{4} \& \mathrm{Au}$ & HeLa cells & Mono & $808 \mathrm{~nm} 1.6 \mathrm{~W} / \mathrm{cm}^{2} 15 \mathrm{~min} \rightarrow$ cell viability assays & {$[147]$} \\
\hline Core@shell & $\mathrm{Fe}_{3} \mathrm{O}_{4} \& \mathrm{Au}$ & HeLa cells & Dual & $350-800 \mathrm{~nm} 3 \mathrm{~mW} / \mathrm{cm}^{2}$ and $560 \mathrm{kHz} 7 \mathrm{~V} 0.8 \mathrm{~A} 5 \mathrm{~min} \rightarrow$ cell viability assays & [121] \\
\hline Multicore@shell & $\mathrm{Fe}_{3} \mathrm{O}_{4} \& \mathrm{Au}$ & In vivo & Dual & $680 \mathrm{~nm} 0.3 \mathrm{~W} / \mathrm{cm}^{2}$ and $110 \mathrm{kHz} 25 \mathrm{mT} 2 \mathrm{~min} \rightarrow 20{ }^{\circ} \mathrm{C}$ & [143] \\
\hline Core@shell & $\mathrm{Fe}_{3} \mathrm{O}_{4} \& \mathrm{Au}-\mathrm{C} 225$ & $\begin{array}{l}\text { U251 cells } \\
\text { in vivo }\end{array}$ & Mono & $635 \mathrm{~nm} 0.3 \mathrm{~W} / \mathrm{cm}^{2}$ and $230 \mathrm{kHz} \mathrm{30A} \rightarrow$ cell viability assays & {$[142]$} \\
\hline
\end{tabular}


I
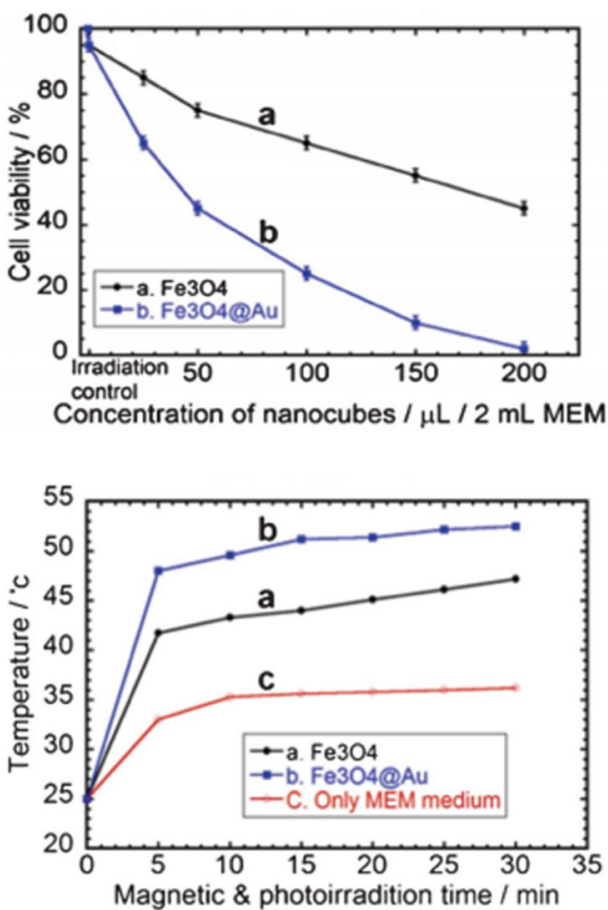

II
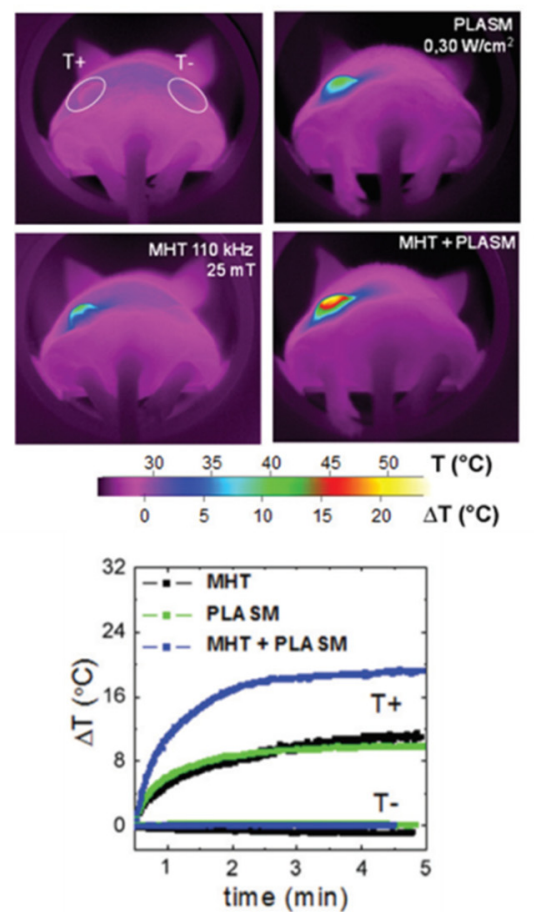

III

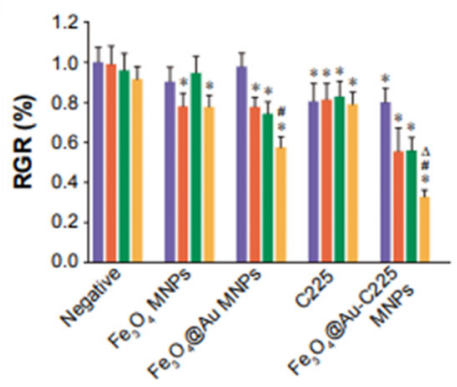

口 Nonhyperthermia $\square$ NIR-hyperthermia

- AMF-hyperthermia 口AMF+NIR

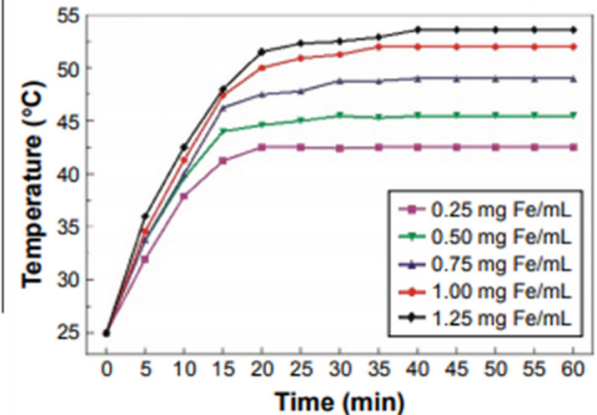

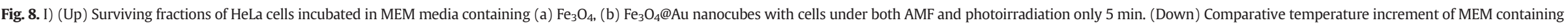

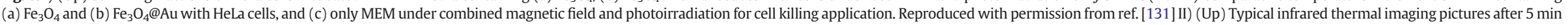

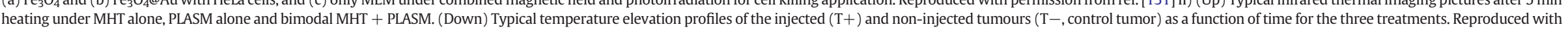

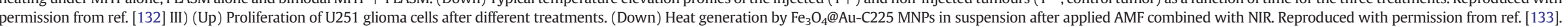


[142] have developed another magnetoplasmonic therapeutic platform for tumor therapy based on $\mathrm{Fe}_{3} \mathrm{O}_{4} @ A u-C 225$ composite-targeted MNPs. The drug C225 was physically adsorbed to the surface of $\mathrm{Fe}_{3} \mathrm{O}_{4} @ \mathrm{Au}-$ C225 MNPs. Furthermore, the dual magnetic and photothermal action mediated by $\mathrm{Fe}_{3} \mathrm{O}_{4} @ \mathrm{Au}-\mathrm{C} 225$ composite-targeted MNPs resulted in intrinsic apoptosis of U251 cells in vitro and growth suppression of tumor in vivo, which showed remarkable improvement in synergistic therapeutic effects for glioma treatment (Fig. 8.III).

\section{Conclusion and outlook}

Despite the recent progress in heat generating MNPs, challenges need to be addressed for the biomedical applications of magnetothermal effects of MNPs in biological systems. Although local thermal effect is very appealing for the next generation of magnetic carriers, these systems still need more investigations toward the understanding of very specific effects. Similarly, the "hot-spot" effect has been explored and its effect was deduced indirectly from macroscopic measurements, yet the local temperature profile around the nanoparticles still requires to be fully documented and understood. In brief, different approaches were conducted to demonstrate first indirect effects of the local heating process. Then, measurements were achieved with various probes to provide the temperature gradient at the surface of MNPs, at different spatial resolution. However, experiments that could give the temperature gradient from the MNPs surface to far apart (few hundred nanometers) are still missing. There also remains plenty to be done concerning the modeling of the nanoscale temperature gradient to confront experimental data depending both on the nature of magnetic particles (free processing or Brownian rotation) and on magnetic stimulation conditions. It would also be quite interesting to measure the nanoscale thermal effect under MHT coupled to methods as dynamic light scattering where the scattering coefficient could indicate the local variation of temperature around nano-antennas [148].

Macromolecular polymers are flexible and efficient nanoplatforms for drug encapsulation and delivery compared to inorganic nanoparticles. However, despite the large portfolio of thermoresponsive nanosystems tested in vitro, only few studies have demonstrated the efficacy of AMF for in vivo drug release. Moreover, the mechanism of molecule release can be very complex. Understanding the diffusion of molecules through the matrix, swelling of the matrix and the chemical reactivity between the molecules and polymer chains (formation of hydrogen bonds, or electrostatic interactions) would be necessary to modulate and regulate the amount of drug released by such platforms [149-151].

On the level of MIPs for drug delivery applications, since the devices are used in an aqueous environment, it would be generally preferable to carry out the imprinting in water. Practical demonstrations of imprinting in water have thus been rather limited to date. Among the best examples of molecular imprinting in aqueous environment are those following the studies of Tanaka et al. [152]. Similar approaches can thus be adopted in the design of MIPs to be used in biological media. In addition, biodegradable polymers, and the potential for biodegradable MIPs, would provide further flexibility in polymer morphology and the resulting dosage form.

It is also desirable to control pore size and volume in these crosslinked gels, perhaps in a way that allows the pores to be opened and closed in response to a local change.

Concerning the global efficacy of thermal treatments, it should be noted that, while a great number of reports have considered the modulation of the magnetic properties for increasing MHT through the design and synthesis of MNPs, recently, MNPs have also been envisaged as promising agents for photothermal therapy [153-155].

Besides, Espinosa et al. [140] have demonstrated the amplification of heating efficiency by MHT and PTT bimodal treatment using magnetite iron oxide nanocubes. Further understanding of the mechanisms behind the heating and the design of stable magnetite NPs toward oxidation may allow to enlarge the panel of applications.
Gold based magnetoplasmonic materials seem also a promising approach and alternative to hurdle the limitations of MHT. However, to date their applications are still limited to the NIR-I window where scattering is strong in biological media. Semiconductor and plasmonic nanoparticles such as substoichiometric copper sulfide compounds $\left(\mathrm{Cu}_{2-\mathrm{x}} \mathrm{S}\right)$ may represent concurrent candidates for efficient PTT, as well as photo-acoustic imaging with deep penetration [156]. Compared to available gold nanoparticles with dimensions suitable for biomedical applications, $\mathrm{Cu}_{2-x} \mathrm{~S}$ semiconductor nanomaterials exhibit fine-tune localized surface plasmon resonance and large extinction coefficients in the second NIR biological window (NIR-II). In this region the imaging resolution (signal-to-noise ratio) is high and light has its maximum depth of penetration in tissues due to the reduction in the intensity of auto fluorescence and the absorption/scattering of photons [157] . Moreover, copper sulfide is biodegradable and its synthesis cost is much cheaper than gold ( $1 \mathrm{~mol}$ of $\mathrm{CuS}$ is US $\$ 330$, and $1 \mathrm{~mol}$ of $\mathrm{Au}$ costs US \$52,200) [158], which is an important criteria for clinical translation and long-term applications. Such plasmonic semiconductors may also allow to combine other modalities on the same nanohybrid for multitherapy such as photodynamic therapy (PDT) while decreasing the dose in NPs.

\section{References}

[1] R. Hergt, S. Dutz, Magnetic particle hyperthermia-biophysical limitations of a visionary tumour therapy, Proc. Sixth Int. Conf. Sci. Clin. Appl. Magn. Carr. 311 (2007) 187-192, https://doi.org/10.1016/j.jmmm.2006.10.1156.

[2] B. Thiesen, A. Jordan, Clinical applications of magnetic nanoparticles for hyperthermia, Int. J. Hyperth. 24 (2008) 467-474, https://doi.org/10.1080/ 02656730802104757.

[3] S. Dutz, R. Hergt, Magnetic nanoparticle heating and heat transfer on a microscale: basic principles, realities and physical limitations of hyperthermia for tumour therapy, Int. J. Hyperth. 29 (2013) 790-800, https://doi.org/10.3109/02656736.2013. 822993.

[4] W. Fan, B. Yung, P. Huang, X. Chen, Chemical reviews, Nanotechnology for Multimodal Synergistic Cancer 117 (2017) 13566-13638.

[5] R. Di Corato, A. Espinosa, L. Lartigue, M. Tharaud, S. Chat, T. Pellegrino, C. Ménager, F. Gazeau, C. Wilhelm, Magnetic hyperthermia efficiency in the cellular environment for different nanoparticle designs, Biomaterials 35 (2014) 6400-6411, https://doi.org/10.1016/j.biomaterials.2014.04.036.

[6] C. Guibert, V. Dupuis, V. Peyre, J. Fresnais, Hyperthermia of magnetic Nanoparticles: an Experimental Study of the Role of Aggregation, J. Phys. Chem. C 119 (2015) 28148-28154, https://doi.org/10.1021/acs.jpcc.5b07796.

[7] C. Yadel, A. Michel, S. Casale, J. Fresnais, Hyperthermia efficiency of magnetic nanoparticles in dense aggregates of cerium oxide/iron oxide nanoparticles, Appl. Sci. 8 (2018) 1241.

[8] H. Huang, S. Delikanli, H. Zeng, D.M. Ferkey, A. Pralle, Remote control of ion channels and neurons through magnetic-field heating of nanoparticles, Nat Nano. 5 (2010) 602-606, https://doi.org/10.1038/nnano.2010.125.

[9] T.T.T. N'Guyen, H.T.T. Duong, J. Basuki, V. Montembault, S. Pascual, C. Guibert, J. Fresnais, C. Boyer, M.R. Whittaker, T.P. Davis, L. Fontaine, Functional iron oxide magnetic nanoparticles with hyperthermia-induced drug release ability by using a combination of orthogonal click reactions, Angew. Chem. Int. Ed. 52 (2013) 14152-14156, https://doi.org/10.1002/anie.201306724.

[10] B. Rühle, S. Datz, C. Argyo, T. Bein, J.I. Zink, A molecular nanocap activated by superparamagnetic heating for externally stimulated cargo release, Chem. Commun. 52 (2016) 1843-1846, https://doi.org/10.1039/C5CC08636A.

[11] D.H. Ortgies, F.J. Teran, U. Rocha, L. de la Cueva, G. Salas, D. Cabrera, A.S. Vanetsev, M. Rähn, V. Sammelselg, Y.V. Orlovskii, D. Jaque, Optomagnetic nanoplatforms for in situ controlled hyperthermia, Adv. Funct. Mater. 28 (2018), 1704434. https:// doi.org/10.1002/adfm.201704434.

[12] L. Polo-Corrales, C. Rinaldi, Monitoring iron oxide nanoparticle surface temperature in an alternating magnetic field using thermoresponsive fluorescent polymers, J. Appl. Phys. 111 (2012), 07B334. https://doi.org/10.1063/1.3680532.

[13] N. Griffete, J. Fresnais, A. Espinosa, C. Wilhelm, A. Bee, C. Menager, Design of magnetic molecularly imprinted polymer nanoparticles for controlled release of doxorubicin under an alternative magnetic field in athermal conditions, Nanoscale (2015)https://doi.org/10.1039/C5NR06133D.

[14] N. Griffete, J. Fresnais, A. Espinosa, D. Taverna, C. Wilhelm, C. Menager, Thermal Polymerization on the Surface of Iron Oxide Nanoparticles Mediated by magnetic Hyperthermia: Implications for Multi-Shell Grafting and Environmental applications, ACS Appl. Nano Mater. (2018)https://doi.org/10.1021/acsanm.7b00063.

[15] E. Guisasola, A. Baeza, M. Talelli, D. Arcos, M. Moros, J.M. de la Fuente, M. ValletRegí, Magnetic-responsive release controlled by hot spot effect, Langmuir 31 (2015) 12777-12782, https://doi.org/10.1021/acs.langmuir.5b03470.

[16] J. Dong, J.I. Zink, Taking the temperature of the interiors of magnetically heated nanoparticles, ACS Nano 8 (2014) 5199-5207, https://doi.org/10.1021/ nn501250e. 
[17] D. Gareau, A. Desrosiers, A. Vallée-Bélisle, Programmable quantitative DNA nanothermometers, Nano Lett. 16 (2016) 3976-3981, https://doi.org/10.1021/ acs.nanolett.6b00156.

[18] J.T. Dias, M. Moros, P. del Pino, S. Rivera, V. Grazú, J.M. de la Fuente, DNA as a molecular local thermal probe for the analysis of magnetic hyperthermia, Angew. Chem. Int. Ed. 52 (2013)https://doi.org/10.1002/anie.201308149.

[19] L. Yu, J. Liu, K. Wu, T. Klein, Y. Jiang, J.-P. Wang, Evaluation of hyperthermia of magnetic nanoparticles by Dehydrating DNA, Sci. Rep. 4 (2014), 7216. https://doi.org/ 10.1038/srep07216.

[20] A. Riedinger, P. Guardia, A. Curcio, M.A. Garcia, R. Cingolani, L. Manna, T. Pellegrino, Subnanometer local temperature probing and remotely controlled drug release based on azo-functionalized iron oxide nanoparticles, Nano Lett. 13 (2013) 2399-2406, https://doi.org/10.1021/nl400188q.

[21] D. Mertz, O. Sandre, S. Bégin-Colin, Drug releasing nanoplatforms activated by alternating magnetic fields, Biochim. Biophys. Acta BBA - Gen. Subj. 1861 (2017) 1617-1641, https://doi.org/10.1016/j.bbagen.2017.02.025.

[22] H. Wu, G. Liu, S. Zhang, J. Shi, L. Zhang, Y. Chen, F. Chen, H. Chen, Biocompatibility, MR imaging and targeted drug delivery of a rattle-type magnetic mesoporous silica nanosphere system conjugated with PEG and cancer-cell-specific ligands, J. Mater. Chem. 21 (2011) 3037-3045, https://doi.org/10.1039/C0JM02863K.

[23] A. Baeza, E. Guisasola, E. Ruiz-Hernández, M. Vallet-Regí, Magnetically triggered multidrug release by hybrid mesoporous silica nanoparticles, Chem. Mater. 24 (2012) 517-524, https://doi.org/10.1021/cm203000u.

[24] F. Lu, A. Popa, S. Zhou, J.-J. Zhu, A.C.S. Samia, Iron oxide-loaded hollow mesoporous silica nanocapsules for controlled drug release and hyperthermia, Chem. Commun. 49 (2013) 11436-11438, https://doi.org/10.1039/C3CC46658B.

[25] K. Chatterjee, S. Sarkar, K. Jagajjanani Rao, S. Paria, Core/shell nanoparticles in biomedical applications, Adv. Colloid Interf. Sci. 209 (2014) 8-39, https://doi.org/10. 1016/j.cis.2013.12.008

[26] E. Bagheri, L. Ansari, K. Abnous, S.M. Taghdisi, F. Charbgoo, M. Ramezani, M. Alibolandi, Silica based hybrid materials for drug delivery and bioimaging, J. Control. Release 277 (2018) 57-76, https://doi.org/10.1016/j.jconrel.2018.03.014.

[27] D. Mertz, O. Sandre, S. Bégin-Colin, Drug releasing nanoplatforms activated by alternating magnetic fields, Recent Adv. Bionanomaterials. 1861 (2017) 1617-1641, https://doi.org/10.1016/j.bbagen.2017.02.025.

[28] A. Kondo, H. Kamura, K. Higashitani, Development and application of thermosensitive magnetic immunomicrospheres for antibody purification, Appl. Microbiol. Biotechnol. 41 (1994) 99-105, https://doi.org/10.1007/BF00166089.

[29] A. Kondo, H. Fukuda, Preparation of thermo-sensitive magnetic hydrogel microspheres and application to enzyme immobilization, J. Ferment. Bioeng. 84 (1997) 337-341, https://doi.org/10.1016/S0922-338X(97)89255-0.

[30] M.K. Jaiswal, S. Mehta, R. Banerjee, D. Bahadur, A comparative study on thermoresponsive magnetic nanohydrogels: role of surface-engineered magnetic nanoparticles, Colloid Polym. Sci. 290 (2012) 607-617, https://doi.org/10.1007/ s00396-011-2572-z.

[31] J. Zhang, S. Xu, E. Kumacheva, Polymer microgels: reactors for semiconductor, metal, and magnetic nanoparticles, J. Am. Chem. Soc. 126 (2004) 7908-7914 https://doi.org/10.1021/ja031523k.

[32] D. Suzuki, H. Kawaguchi, Modification of gold nanoparticle composite nanostructures using thermosensitive core-shell particles as a template, Langmuir 21 (2005) 8175-8179, https://doi.org/10.1021/la0504356.

[33] D. Suzuki, H. Kawaguchi, Stimuli-sensitive core/shell template particles for immobilizing inorganic nanoparticles in the core, Colloid Polym. Sci. 284 (2006) 1443-1451, https://doi.org/10.1007/s00396-006-1523-6.

[34] D. Suzuki, H. Kawaguchi, Hybrid microgels with reversibly changeable multiple brilliant color, Langmuir 22 (2006) 3818-3822, https://doi.org/10.1021/la052999f.

[35] F. Sauzedde, A. Elaïssari, C. Pichot, Hydrophilic magnetic polymer latexes. 1. Adsorption of magnetic iron oxide nanoparticles onto various cationic latexes, Colloid Polym. Sci. 277 (1999) 846-855, https://doi.org/10.1007/s003960050461.

[36] F. Sauzedde, A. Elaïssari, C. Pichot, Hydrophilic magnetic polymer latexes. 2. Encapsulation of adsorbed iron oxide nanoparticles, Colloid Polym. Sci. 277 (1999) 1041-1050, https://doi.org/10.1007/s003960050488.

[37] R. Regmi, S.R. Bhattarai, C. Sudakar, A.S. Wani, R. Cunningham, P.P. Vaishnava, R. Naik, D. Oupicky, G. Lawes, Hyperthermia controlled rapid drug release from thermosensitive magnetic microgels, J. Mater. Chem. 20 (2010) 6158, https://doi. org/10.1039/c0jm00844c.

[38] M.K. Jaiswal, M. De, S.S. Chou, S. Vasavada, R. Bleher, P.V. Prasad, D. Bahadur, V.P. Dravid, Thermoresponsive magnetic hydrogels as theranostic nanoconstructs, ACS Appl. Mater. Interfaces 6 (2014) 6237-6247, https://doi.org/10.1021/ am501067j.

[39] J.E. Wong, A. Krishnakumar Gaharwar, D. Müller-Schulte, D. Bahadur, W. Richtering, Layer-by-layer assembly of a magnetic nanoparticle shell on a thermoresponsive microgel core, J. Magn. Magn. Mater. 311 (2007) 219-223, https://doi.org/10.1016/j.jmmm.2006.10.1201.

[40] H. Vihola, A. Laukkanen, L. Valtola, H. Tenhu, J. Hirvonen, Cytotoxicity of thermosensitive polymers poly( $\mathrm{N}$-isopropylacrylamide), poly(N-vinylcaprolactam) and amphiphilically modified poly(N-vinylcaprolactam), Biomaterials 26 (2005) 3055-3064, https://doi.org/10.1016/j.biomaterials.2004.09.008.

[41] A.S. Wadajkar, B. Koppolu, M. Rahimi, K.T. Nguyen, Cytotoxic evaluation of Nisopropylacrylamide monomers and temperature-sensitive poly(Nisopropylacrylamide) nanoparticles, J. Nanopart. Res. 11 (2009) 1375-1382, https://doi.org/10.1007/s11051-008-9526-5.

[42] H. Bianco-Peled, S. Gryc, Binding of amino acids to "smart" sorbents: where does hydrophobicity come into play? Langmuir 20 (2004) 169-174, https://doi.org/ 10.1021/la0357155.
[43] S. Brulé, M. Levy, C. Wilhelm, D. Letourneur, F. Gazeau, C. Ménager, C. Le Visage, Doxorubicin release triggered by alginate embedded magnetic nanoheaters: a combined therapy, Adv. Mater. 23 (2011) 787-790, https://doi.org/10.1002/ adma.201003763.

[44] J.-F. Lutz, Polymerization of oligo(ethylene glycol) (meth)acrylates: toward new generations of smart biocompatible materials, J. Polym. Sci. Part Polym. Chem. 46 (2008) 3459-3470, https://doi.org/10.1002/pola.22706.

[45] J.-F. Lutz, Thermo-Switchable Materials prepared using the OEGMA-Platform, Adv Mater. 23 (2011) 2237-2243, https://doi.org/10.1002/adma.201100597.

[46] T. McCallister, E. Gidney, D. Adams, D.R. Diercks, S. Ghosh, Engineered thermoresponsive, magnetic nanocarriers of oligo(ethylene glycol)-methacrylate-based biopolymers, Appl. Phys. Express 7 (2014), 117003. https://doi.org/10. 7567/APEX.7.117003.

[47] E. Cazares-Cortes, A. Espinosa, J.-M. Guigner, A. Michel, N. Griffete, C. Wilhelm, C. Ménager, Doxorubicin intracellular remote release from biocompatible oligo(ethylene glycol) methyl ether methacrylate-based magnetic nanogels triggered by magnetic hyperthermia, ACS Appl. Mater. Interfaces 9 (2017) 25775-25788, https://doi.org/10.1021/acsami.7b06553.

[48] M. Molina, M. Asadian-Birjand, J. Balach, J. Bergueiro, E. Miceli, M. Calderón, Stimuli-responsive nanogel composites and their application in nanomedicine, Chem. Soc. Rev. (2015)https://doi.org/10.1039/C5CS00199D.

[49] H. Yang, O. Wang, S. Huang, A. Xiao, F. Li, L. Gan, X. Yang, Smart pH/Redox Dualresponsive nanogels for on-demand intracellular anticancer drug release, ACS Appl. Mater. Interfaces 8 (2016) 7729-7738, https://doi.org/10.1021/acsami. 6b01602.

[50] A. Álvarez-Bautista, C.M.M. Duarte, E. Mendizábal, I. Katime, Controlled delivery of drugs through smart $\mathrm{pH}$-sensitive nanohydrogels for anti-cancer therapies: synthesis, drug release and cellular studies, Des. Monomers Polym. 19 (2016) 319-329, https://doi.org/10.1080/15685551.2016.1152542.

[51] S. Mura, J. Nicolas, P. Couvreur, Stimuli-responsive nanocarriers for drug delivery, Nat. Mater. 12 (2013) 991-1003, https://doi.org/10.1038/nmat3776.

[52] Mai, et al., Nanosystems Based on Magnetic Nanoparticles and Th.pdf, 2018.

[53] K. Hayashi, M. Nakamura, H. Miki, S. Ozaki, M. Abe, T. Matsumoto, W. Sakamoto, T. Yogo, K. Ishimura, Magnetically responsive smart nanoparticles for cancer treatment with a combination of magnetic hyperthermia and remote-control drug release, Theranostics. 4 (2014) 834-844, https://doi.org/10.7150/thno.9199.

[54] H.-Y. Huang, S.-H. Hu, C.-S. Chian, S.-Y. Chen, H.-Y. Lai, Y.-Y. Chen, Self-assembling PVA-F127 thermosensitive nanocarriers with highly sensitive magneticallytriggered drug release for epilepsy therapy in vivo, J. Mater. Chem. 22 (2012) 8566-8573, https://doi.org/10.1039/C2JM00032F.

[55] Zhang Song, Multiple hyperthermia-mediated release of TRAILSP.pdf, 2017 (n.d.)

[56] M.V. Polyakov, Adsorption properties and structure of silica gel, Zhur Fiz Khim. 2 (1931) 799-805.

[57] F.H. Dickey, The preparation of specific adsorbents, Proc. Natl. Acad. Sci. 35 (1949) 227-229.

[58] G. Wulff, A. Sarhan, Über die Anwendung von enzymanalog gebauten Polymeren zur Racemattrennung, Angew. Chem. 84 (1972) 364, https://doi.org/10.1002/ ange.19720840838.

[59] G. Wulff, J. Haarer, Enzyme-analogue built polymers, 29. The preparation of defined chiral cavities for the racemic resolution of free sugars, Makromol. Chem. 192 (1991) 1329-1338, https://doi.org/10.1002/macp.1991.021920610.

[60] Q. Yang, J. Li, X. Wang, H. Peng, H. Xiong, L. Chen, Strategies of molecular imprinting-based fluorescence sensors for chemical and biological analysis, Biosens. Bioelectron. 112 (2018) 54-71, https://doi.org/10.1016/j.bios.2018.04 028.

[61] X.-M. Zhang, Y.-P. Qin, H.-L. Ye, X.-T. Ma, X.-W. He, W.-Y. Li, Y.-K. Zhang, Silicon nanoparticles coated with an epitope-imprinted polymer for fluorometric determination of cytochrome c, Microchim. Acta 185 (2018), 173. https://doi.org/10. 1007/s00604-018-2724-7.

[62] G. Vlatakis, L.I. Andersson, R. Müller, K. Mosbach, Drug assay using antibody mimics made by molecular imprinting, Nature 361 (1993) 645-647, https://doi. org/10.1038/361645a0.

[63] G. Wulff, Enzyme-like catalysis by molecularly imprinted polymers, Chem. Rev 102 (2002) 1-28, https://doi.org/10.1021/cr980039a.

[64] B.B. Prasad, M.P. Tiwari, R. Madhuri, P.S. Sharma, Enatioselective quantitative separation of d- and l-thyroxine by molecularly imprinted micro-solid phase extraction silver fiber coupled with complementary molecularly imprinted polymersensor, J. Chromatogr. A 1217 (2010) 4255-4266, https://doi.org/10.1016/j. chroma.2010.04.055.

[65] X.-J. Kong, C. Zheng, Y.-H. Lan, S.-S. Chi, Q. Dong, H.-L. Liu, C. Peng, L.-Y. Dong, L. Xu, X.-H. Wang, Synthesis of multirecognition magnetic molecularly imprinted polymer by atom transfer radical polymerization and its application in magnetic solid-phase extraction, Anal. Bioanal. Chem. 410 (2018) 247-257, https://doi.org/ 10.1007/s00216-017-0716-9.

[66] D. Cunliffe, A. Kirby, C. Alexander, Molecularly imprinted drug delivery systems, Adv. Drug Deliv. Rev. 57 (2005) 1836-1853, https://doi.org/10.1016/j.addr.2005. 07.015 .

[67] C. Alvarez-Lorenzo, A. Concheiro, Molecularly imprinted polymers for drug delivery, J. Chromatogr. B 804 (2004) 231-245, https://doi.org/10.1016/j.jchromb. 2003.12.032.

[68] C.B. Gong, M.H.-W. Lam, H.X. Yu, The fabrication of a photoresponsive molecularly imprinted polymer for the photoregulated uptake and release of caffeine, Adv. Funct. Mater. 16 (2006) 1759-1767, https://doi.org/10.1002/adfm.200500907.

[69] F. Puoci, F. Iemma, G. Cirillo, M. Curcio, O.I. Parisi, U.G. Spizzirri, N. Picci, New restricted access materials combined to molecularly imprinted polymers for selective 
recognition/release in water media, Eur. Polym. J. 45 (2009) 1634-1640, https:// doi.org/10.1016/j.eurpolymj.2009.01.021.

[70] P. Luliński, Molecularly imprinted polymers based drug delivery devices: a way to application in modern pharmacotherapy. A review, Mater. Sci. Eng. C. 76 (2017) 1344-1353, https://doi.org/10.1016/j.msec.2017.02.138.

[71] F. Puoci, F. Iemma, R. Muzzalupo, U.G. Spizzirri, S. Trombino, R. Cassano, N. Picci, Spherical Molecularly Imprinted Polymers (SMIPs) via a novel precipitation polymerization in the controlled delivery of sulfasalazine, Macromol. Biosci. 4 (2004) 22-26, https://doi.org/10.1002/mabi.200300035

[72] R. Suedee, T. Srichana, T. Rattananont, Enantioselective release of controlled delivery granules based on molecularly imprinted polymers, Drug Deliv. 9 (2002) 19-30, https://doi.org/10.1080/107175402753413145.

[73] K. Sreenivasan, Application of molecularly imprinted polymer as a drug retaining matrix, Angew. Makromol. Chem. 246 (1997) 65-69, https://doi.org/10.1002/ apmc.1997.052460105.

[74] M. Watanabe, T. Akahoshi, Y. Tabata, D. Nakayama, Molecular specific swelling change of hydrogels in accordance with the concentration of guest molecules, J. Am. Chem. Soc. 120 (1998) 5577-5578, https://doi.org/10.1021/ja973070n.

[75] S. Venkataraman, J.L. Hedrick, Z.Y. Ong, C. Yang, P.L.R. Ee, P.T. Hammond, Y.Y. Yang, The effects of polymeric nanostructure shape on drug delivery, Adv. Drug Deliv. Rev. 63 (2011) 1228-1246, https://doi.org/10.1016/j.addr.2011.06.016.

[76] Y. Hoshino, H. Koide, T. Urakami, H. Kanazawa, T. Kodama, N. Oku, K.J. Shea, Recognition, neutralization, and clearance of target peptides in the bloodstream of living mice by molecularly imprinted polymer nanoparticles: a plastic antibody, J. Am. Chem. Soc. 132 (2010) 6644-6645, https://doi.org/10.1021/ja102148f.

[77] C. Huang, X. Shen, Janus molecularly imprinted polymer particles, Chem. Commun 50 (2014) 2646-2649, https://doi.org/10.1039/C3CC49586H.

[78] E. Asadi, M. Abdouss, R.M. Leblanc, N. Ezzati, J.N. Wilson, S. Azodi-Deilami, In vitro/ in vivo study of novel anti-cancer, biodegradable cross-linked tannic acid for fabrication of 5-fluorouracil-targeting drug delivery nano-device based on a molecular imprinted polymer, RSC Adv. 6 (2016) 37308-37318, https://doi.org/10.1039/ C6RA03704F.

[79] B. Liu, D. Tang, B. Zhang, X. Que, H. Yang, G. Chen, Au(III)-promoted magnetic molecularly imprinted polymer nanospheres for electrochemical determination of streptomycin residues in food, Biosens. Bioelectron. 41 (2013) 551-556, https:// doi.org/10.1016/j.bios.2012.09.021.

[80] X. Kan, Z. Geng, Y. Zhao, Z. Wang, J.-J. Zhu, Magnetic molecularly imprinted polymer for aspirin recognition and controlled release, Nanotechnology 20 (2009), 165601. https://doi.org/10.1088/0957-4484/20/16/165601.

[81] N. Griffete, J. Fresnais, A. Espinosa, C. Wilhelm, A. Bée, C. Ménager, Design of magnetic molecularly imprinted polymer nanoparticles for controlled release of doxorubicin under an alternative magnetic field in athermal conditions, Nanoscale 7 (2015) 18891-18896, https://doi.org/10.1039/C5NR06133D.

[82] H. Kakwere, M.P. Leal, M.E. Materia, A. Curcio, P. Guardia, D. Niculaes, R. Marotta, A Falqui, T. Pellegrino, Functionalization of strongly Interacting magnetic Nanocube with (Thermo)Responsive Coating and their Application in Hyperthermia and Heat-Triggered Drug delivery, ACS Appl. Mater. Interfaces 7 (2015) 10132-10145, https://doi.org/10.1021/am5088117.

[83] E. Cazares-Cortes, A. Espinosa, J.-M. Guigner, A. Michel, N. Griffete, C. Wilhelm, C. Ménager, Doxorubicin intracellular remote release from biocompatible oligo(ethylene glycol) methyl ether methacrylate-based magnetic nanogels triggered by magnetic hyperthermia, ACS Appl. Mater. Interfaces 9 (2017) 25775-25788, https://doi.org/10.1021/acsami.7b06553.

[84] Z.-Q. Zhang, S.-C. Song, Multiple hyperthermia-mediated release of TRAIL/SPION nanocomplex from thermosensitive polymeric hydrogels for combination cancer therapy, Biomaterials 132 (2017) 16-27, https://doi.org/10.1016/j.biomaterials. 2017.03.049.

[85] C. Blanco-Andujar, F.J. Teran, D. Ortega, Chapter 8 - current outlook and perspectives on nanoparticle-mediated magnetic hyperthermia A2 - Mahmoudi, Morteza in: S. Laurent (Ed.), Iron Oxide Nanoparticles Biomed. Appl. Elsevier 2018 pp. 197-245, https://doi.org/10.1016/B978-0-08-101925-2.00007-3.

[86] S. Noh, S.H. Moon, T.-H. Shin, Y. Lim, J. Cheon, Recent advances of magneto-thermal capabilities of nanoparticles: from design principles to biomedical applications, Nano Today 13 (2017) 61-76, https://doi.org/10.1016/j.nantod.2017.02.006.

[87] A.J. Giustini, A.A. Petryk, S.M. Cassim, J.A. Tate, I. Baker, P.J. Hoopes, Magnetic nanoparticle hyperthermia in cancer treatment, Nano LIFE. 01 (2010) 17-32, https:// doi.org/10.1142/S1793984410000067.

[88] A. Espinosa, J. Kolosnjaj-Tabi, A. Abou-Hassan, A. Plan Sangnier, A. Curcio, A.K.A Silva, R. Di Corato, S. Neveu, T. Pellegrino, L.M. Liz-Marzán, C. Wilhelm, Magnetic (hyper)thermia or photothermia? progressive comparison of iron oxide and gold nanoparticles heating in water, in cells, and in vivo, Adv. Funct. Mater. (2018), 1803660. https://doi.org/10.1002/adfm.201803660.

[89] S. Eustis, M.A. El-Sayed, Why gold nanoparticles are more precious than pretty gold: Noble metal surface plasmon resonance and its enhancement of the radiative and nonradiative properties of nanocrystals of different shapes, Chem. Soc. Rev. 35 (2006) 209-217, https://doi.org/10.1039/B514191E.

[90] A. Moores, F. Goettmann, The plasmon band in noble metal nanoparticles: an in troduction to theory and applications, New J. Chem. 30 (2006) 1121-1132, https://doi.org/10.1039/B604038C.

[91] A. Vincenzo, P. Roberto, F. Marco, M.M. Onofrio, I. Maria Antonia, Surface plasmon resonance in gold nanoparticles: a review, J. Phys. Condens. Matter. 29 (2017), 203002.

[92] K.M. Mayer, J.H. Hafner, Localized surface plasmon resonance sensors, Chem. Rev. 111 (2011) 3828-3857, https://doi.org/10.1021/cr100313v.

[93] C.L. Nehl, J.H. Hafner, Shape-dependent plasmon resonances of gold nanoparticles, J. Mater. Chem. 18 (2008) 2415-2419, https://doi.org/10.1039/B714950F.
[94] H. Chen, X. Kou, Z. Yang, W. Ni, J. Wang, Shape- and size-dependent refractive index sensitivity of gold nanoparticles, Langmuir 24 (2008) 5233-5237, https:// doi.org/10.1021/la800305j.

[95] C.L. Nehl, H. Liao, J.H. Hafner, Optical properties of star-shaped gold nanoparticles, Nano Lett. 6 (2006) 683-688, https://doi.org/10.1021/nl052409y.

[96] A. Tomitaka, H. Arami, A. Raymond, A. Yndart, A. Kaushik, R.D. Jayant, Y. Takemura, Y. Cai, M. Toborek, M. Nair, Development of magneto-plasmonic nanoparticles for multimodal image-guided therapy to the brain, Nanoscale 9 (2017) 764-773, https://doi.org/10.1039/C6NR07520G.

[97] A. Agrawal, S.H. Cho, O. Zandi, S. Ghosh, R.W. Johns, D.J. Milliron, Localized surface plasmon resonance in semiconductor nanocrystals, Chem. Rev. 118 (2018) 3121-3207, https://doi.org/10.1021/acs.chemrev.7b00613.

[98] M. Hu, J. Chen, Z.-Y. Li, L. Au, G.V. Hartland, X. Li, M. Marquez, Y. Xia, Gold nanostructures: engineering their plasmonic properties for biomedical applications, Chem. Soc. Rev. 35 (2006) 1084-1094, https://doi.org/10.1039/B517615H.

[99] A. Genç, J. Patarroyo, J. Sancho-Parramon, R. Arenal, M. Duchamp, E.E. Gonzalez, L. Henrard, N.G. Bastús, R.E. Dunin-Borkowski, V.F. Puntes, J. Arbiol, Tuning the plasmonic response up: hollow cuboid metal nanostructures, ACS Photonics. 3 (2016) 770-779, https://doi.org/10.1021/acsphotonics.5b00667.

[100] H.U. Yang, J. D'Archangel, M.L. Sundheimer, E. Tucker, G.D. Boreman, M.B. Raschke, Optical dielectric function of silver, Phys. Rev. B 91 (2015), 235137. https://doi.org/ 10.1103/PhysRevB.91.235137.

[101] C. Noguez, Surface plasmons on metal nanoparticles: the influence of shape and physical environment, J. Phys. Chem. C 111 (2007) 3806-3819, https://doi.org/ 10.1021/jp066539m.

[102] H. Wang, D.W. Brandl, F. Le, P. Nordlander, N.J. Halas, Nanorice: a hybrid plasmonic nanostructure, Nano Lett. 6 (2006) 827-832, https://doi.org/10.1021/nl060209w.

[103] W.-P. Li, P.-Y. Liao, C.-H. Su, C.-S. Yeh, Formation of Oligonucleotide-gated silica shell-coated Fe304-au Core-Shell nanotrisoctahedra for magnetically targeted and near-infrared light-responsive theranostic platform, J. Am. Chem. Soc. 136 (2014) 10062-10075, https://doi.org/10.1021/ja504118q.

[104] Wang Chungang, Chen Jiji, Talavage Tom, Irudayaraj Joseph, Gold Nanorod/Fe304 Nanoparticle "nano-pearl-necklaces" for simultaneous targeting, dual-mode imaging, and photothermal ablation of cancer cells, Angew. Chem. Int. Ed. 48 (2009) 2759-2763, https://doi.org/10.1002/anie.200805282.

[105] Kim Zhou Hongjian, Bahng Joong Jong-Pil, Kotov Hwan, A. Nicholas, Lee Jaebeom, Self-assembly mechanism of spiky magnetoplasmonic supraparticles, Adv. Funct. Mater. 24 (2014) 1439-1448, https://doi.org/10.1002/adfm.201302405.

[106] Huang Wei-Chieh, Tsai Pei-Jane, Chen Yu-Chie, Multifunctional Fe304@au Nanoeggs as photothermal agents for selective killing of nosocomial and antibiotic-resistant bacteria, Small 5 (2009) 51-56, https://doi.org/10.1002/smll. 200801042.

[107] W. Hui, F. Shi, K. Yan, M. Peng X. Cheng, Y. Luo, X. Chen, V.A.L. Roy, Y. Cui, Z. Wang, Fe304/au/Fe304 nanoflowers exhibiting tunable saturation magnetization and enhanced bioconjugation, Nanoscale 4 (2012) 747-751, https://doi.org/10.1039/ C2NR11489E.

[108] M.D. Scanlon, E. Smirnov, T.J. Stockmann, P. Peljo, Gold Nanofilms at liquid-liquid interfaces: an emerging platform for redox electrocatalysis, nanoplasmonic sensors, and electrovariable optics, Chem. Rev. 118 (2018) 3722-3751, https://doi. org/10.1021/acs.chemrev.7b00595.

[109] H. Zhou, F. Zou, K. Koh, J. Lee, Multifunctional magnetoplasmonic nanomaterials and their biomedical applications, J. Biomed. Nanotechnol. 10 (2014) 2921-2949, https://doi.org/10.1166/jbn.2014.1938.

[110] A.M. Craciun, M. Focsan, K. Magyari, A. Vulpoi, Z. Pap, Surface plasmon resonance or biocompatibility-key properties for determining the applicability of noble metal nanoparticles, Materials. 10 (2017) 836.

[111] Wu Chun-Hsien, Cook Jason, Emelianov Stanislav, Sokolov Konstantin, Multimodal magneto-plasmonic nanoclusters for biomedical applications, Adv. Funct. Mater. 24 (2014) 6862-6871, https://doi.org/10.1002/adfm.201401806.

[112] V.T. Tran, J. Kim, L.T. Tufa, S. Oh, J. Kwon, J. Lee, Magnetoplasmonic nanomaterials for biosensing/imaging and in vitro/in vivo biousability, Anal. Chem. 90 (2018) 225-239, https://doi.org/10.1021/acs.analchem.7b04255.

[113] C. Kennedy Laura, R. Bickford Lissett, A. Lewinski Nastassja, J. Coughlin Andrew, Hu Ying, S. Day Emily, L. West Jennifer, A. Drezek Rebekah, A. New, Era for cancer treatment: gold-nanoparticle-mediated thermal therapies, Small 7 (2011) 169-183, https://doi.org/10.1002/smll.201000134.

[114] H. Daraee, A. Eatemadi, E. Abbasi, S. Fekri Aval, M. Kouhi, A. Akbarzadeh, Application of gold nanoparticles in biomedical and drug delivery, Artif. Cells Nanomedicine Biotechnol. 44 (2016) 410-422, https://doi.org/10.3109/ 21691401.2014.955107

[115] B. Jaber, K. Sara, A. Neda, S. Saeed, S.-Z Ali, G. Habib, G. Hossein, A nanotechnologybased strategy to increase the efficiency of cancer diagnosis and therapy: folateconjugated gold nanoparticles, Curr. Med. Chem. 24 (2017) 4399-4416, https:// doi.org/10.2174/0929867324666170810154917.

[116] F. Mazuel, A. Espinosa, N. Luciani, M. Reffay, R. Le Borgne, L. Motte, K. Desboeufs, A Michel, T. Pellegrino, Y. Lalatonne, C. Wilhelm, Massive Intracellular Biodegradation of Iron Oxide nanoparticles evidenced magnetically at single-endosome and tissue levels, ACS Nano 10 (2016) 7627-7638, https://doi.org/10.1021/acsnano. $6 \mathrm{~b} 02876$.

[117] T.T. Nguyen, F. Mammeri, S. Ammar, Iron oxide and gold based magnetoplasmonic nanostructures for medical applications: a review, Nano 8 (2018) https://doi.org/10.3390/nano8030149.

[118] T. Nguyen, F. Mammeri, S. Ammar, Iron oxide and gold based magneto-plasmonic nanostructures for medical applications: a review, Nano 8 (2018) 149.

[119] Yang Di, Pang Xinchang, He Yanjie, Wang Yiquan, Chen Genxiang, Wang Wenzhong, Lin Zhiqun, Precisely size-tunable magnetic/plasmonic core/shell 
nanoparticles with controlled optical properties, Angew. Chem. 127 (2015) 12259-12264, https://doi.org/10.1002/ange.201504676.

[120] C.S. Levin, C. Hofmann, T.A. Ali, A.T. Kelly, E. Morosan, P. Nordlander, K.H. Whitmire, N.J. Halas, Magnetic-plasmonic core-shell nanoparticles, ACS Nano 3 (2009) 1379-1388, https://doi.org/10.1021/nn900118a.

[121] M. Abdulla-Al-Mamun, Y. Kusumoto, T. Zannat, Y. Horie, H. Manaka, Au-ultrathin functionalized core-shell (Fe304@au) monodispersed nanocubes for a combination of magnetic/plasmonic photothermal cancer cell killing, RSC Adv. 3 (2013) 7816-7827, https://doi.org/10.1039/C3RA21479F.

[122] L. Lou, K. Yu, Z. Zhang, R. Huang, Y. Wang, Z. Zhu, Facile methods for synthesis of core-shell structured and heterostructured Fe304@au nanocomposites, Appl. Surf. Sci. 258 (2012) 8521-8526, https://doi.org/10.1016/j.apsusc.2012.05.031.

[123] M. Wang, C. Wang, K.L. Young, L. Hao, M. Medved, T. Rajh, H.C. Fry, L. Zhu, G.S. Karczmar, C. Watson, J.S. Jiang, N.M. Markovic, V.R. Stamenkovic, Cross-linked Heterogeneous Nanoparticles as Bifunctional Probe, Chem. Mater. 24 (2012) 2423-2425, https://doi.org/10.1021/cm300381f.

[124] Z. Cai, E.S.P. Leong, Z. Wang, W. Niu, W. Zhang, S. Ravaine, N.L. Yakovlev, Y.J. Liu, J. Teng, X. Lu, Sandwich-structured Fe2O3@SiO2@au nanoparticles with magnetoplasmonic responses, J. Mater. Chem. C 3 (2015) 11645-11652, https:// doi.org/10.1039/C5TC01259G.

[125] F. Chen, Q. Chen, S. Fang, Y. Sun, Z. Chen, G. Xie, Y. Du, Multifunctional nanocomposites constructed from Fe304-au nanoparticle cores and a porous silica shell in the solution phase, Dalton Trans. 40 (2011) 10857-10864, https://doi.org/10. 1039/C1DT10374A.

[126] L. Zhou, J. Yuan, Y. Wei, Core-shell structural iron oxide hybrid nanoparticles: from controlled synthesis to biomedical applications, J. Mater. Chem. 21 (2011) 2823-2840, https://doi.org/10.1039/COJM02172E.

[127] K. Chatterjee, S. Sarkar, K. Jagajjanani Rao, S. Paria, Core/shell nanoparticles in biomedical applications, Adv. Colloid Interf. Sci. 209 (2014) 8-39, https://doi.org/10. 1016/j.cis.2013.12.008.

[128] J. Li, Y. Hu, J. Yang, P. Wei, W. Sun, M. Shen, G. Zhang, X. Shi, Hyaluronic acidmodified Fe304@au core/shell nanostars for multimodal imaging and photothermal therapy of tumors, Biomaterials 38 (2015) 10-21, https://doi.org/ 10.1016/j.biomaterials.2014.10.065.

[129] A. Goyal, R. Sharma, S. Bansal, K.B. Tikoo, V. Kumar, S. Singhal, Functionalized coreshell nanostructures with inherent magnetic character: Outperforming candidates for the activation of PMS, Adv. Powder Technol. 29 (2018) 245-256, https://doi. org/10.1016/j.apt.2017.11.008.

[130] K.C.-F. Leung, S. Xuan, X. Zhu, D. Wang, C.-P. Chak, S.-F. Lee, W.K.W. Ho, B.C.T. Chung, Gold and iron oxide hybrid nanocomposite materials, Chem. Soc. Rev. 41 (2012) 1911-1928, https://doi.org/10.1039/C1CS15213K.

[131] Lim Jitkang, Eggeman Alexander, Lanni Frederick, D. Tilton Robert, A. Majetich Sara, Synthesis and Single-Particle Optical Detection of Low-Polydispersity Plasmonic-Superparamagnetic Nanoparticles, Adv. Mater. 20 (2008) 1721-1726, https://doi.org/10.1002/adma.200702196.

[132] W. Fang, H. Zhang, X. Wang, W. Wei, Y. Shen, J. Yu, J. Liang, J. Zheng, Y. Shen, Facile synthesis of tunable plasmonic silver core/magnetic Fe304 shell nanoparticles for rapid capture and effective photothermal ablation of bacterial pathogens, New J. Chem. 41 (2017) 10155-10164, https://doi.org/10.1039/C7NJ02071F.

[133] M. Takahashi, P. Mohan, A. Nakade, K. Higashimine, D. Mott, T. Hamada, K. Matsumura, T. Taguchi, S. Maenosono, Ag/FeCo/Ag core/shell/shell magnetic nanoparticles with plasmonic imaging capability, Langmuir 31 (2015) 2228-2236, https://doi.org/10.1021/la5046805.

[134] A. Tomitaka, H. Arami, Z. Huang, A. Raymond, E. Rodriguez, Y. Cai, M. Febo, Y. Takemura, M. Nair, Hybrid magneto-plasmonic liposomes for multimodal imageguided and brain-targeted HIV treatment, Nanoscale 10 (2018) 184-194, https:// doi.org/10.1039/C7NR07255D.

[135] M. Ravichandran, G. Oza, S. Velumani, J.T. Ramirez, A. Vera, L. Leija, Design and evaluation of surface functionalized superparamagneto-plasmonic nanoparticles for cancer therapeutics, Int. J. Pharm. 524 (2017) 16-29, https://doi.org/10.1016/ j.ijpharm.2017.03.071.

[136] T. Zhou, B. Wu, D. Xing, Bio-modified Fe3O4 core/au shell nanoparticles for targeting and multimodal imaging of cancer cells, J. Mater. Chem. 22 (2012) 470-477, https://doi.org/10.1039/C1JM13692E.

[137] X. Hou, X. Wang, R. Liu, H. Zhang, X. Liu, Y. Zhang, Facile synthesis of multifunctional Fe304@SiO2@au magneto-plasmonic nanoparticles for MR/CT dual imaging and photothermal therapy, RSC Adv. 7 (2017) 18844-18850, https://doi.org/10. 1039/C7RA00925A.

[138] Z. Fan, M. Shelton, A.K. Singh, D. Senapati, S.A. Khan, P.C. Ray, Multifunctional plasmonic shell-magnetic core nanoparticles for targeted diagnostics, isolation, and photothermal destruction of tumor cells, ACS Nano 6 (2012) 1065-1073, https:// doi.org/10.1021/nn2045246.

[139] L. Li, S. Fu, C. Chen, X. Wang, C. Fu, S. Wang, W. Guo, X. Yu, X. Zhang, Z. Liu, J. Qiu, H. Liu, Microenvironment-driven bioelimination of magnetoplasmonic nanoassemblies and their multimodal imaging-guided tumor photothermal therapy, ACS Nano 10 (2016) 7094-7105, https://doi.org/10.1021/acsnano.6b03238.

[140] A. Espinosa, M. Bugnet, G. Radtke, S. Neveu, G.A. Botton, C. Wilhelm, A. AbouHassan, Can magneto-plasmonic nanohybrids efficiently combine photothermia with magnetic hyperthermia? Nanoscale 7 (2015) 18872-18877, https://doi.org/ 10.1039/C5NR06168G.

[141] F. Mazuel, A. Espinosa, G. Radtke, M. Bugnet, S. Neveu, Y. Lalatonne, G.A. Botton, A Abou-Hassan, C. Wilhelm, Magneto-thermal metrics can mirror the long-term intracellular fate of magneto-plasmonic nanohybrids and reveal the remarkable shielding effect of gold, Adv. Funct. Mater. 27 (2017), 1605997. https://doi.org/ 10.1002/adfm.201605997.

[142] D.X. Lu, Fe304@au composite magnetic nanoparticles modified with cetuximab for targeted magneto-photothermal therapy of glioma cells, Int. J. Nanomedicine 13 (2018) 2491-2505, https://doi.org/10.2147/IJN.S157935.

[143] A. Espinosa, M. Bugnet, G. Radtke, S. Neveu, G.A. Botton, C. Wilhelm, A. AbouHassan, Can magneto-plasmonic nanohybrids efficiently combine photothermia with magnetic hyperthermia? Nanoscale 7 (2015) 18872-18877, https://doi.org/ 10.1039/C5NR06168G

[144] D.K. Kirui, I. Khalidov, Y. Wang, C.A. Batt, Targeted near-IR hybrid magnetic nanoparticles for in vivo cancer therapy and imaging, Nanomed. 9 (2013) 702-711, https://doi.org/10.1016/j.nano.2012.11.009.

[145] Bardhan Rizia, Chen Wenxue, Perez-Torres Carlos, Bartels Marc, M. Huschka Ryan, L. Zhao Liang, Morosan Emilia, G. Pautler Robia, Joshi Amit, J. Halas Naomi, Nanoshells with targeted simultaneous enhancement of magnetic and optical imaging and photothermal therapeutic response, Adv. Funct. Mater. 19 (2009) 3901-3909, https://doi.org/10.1002/adfm.200901235.

[146] X. Wang, H. Liu, D. Chen, X. Meng, T. Liu, C. Fu, N. Hao, Y. Zhang, X. Wu, J. Ren, F. Tang, Multifunctional Fe304@P(St/MAA)@Chitosan@au Core/Shell Nanoparticles for dual Imaging and Photothermal Therapy, ACS Appl. Mater. Interfaces 5 (2013) 4966-4971, https://doi.org/10.1021/am400721s.

[147] Y. Hu, L. Meng, L. Niu, Q. Lu, Facile Synthesis of Superparamagnetic Fe304@ polyphosphazene@au Shells for magnetic Resonance Imaging and Photothermal Therapy, ACS Appl. Mater. Interfaces 5 (2013) 4586-4591, https://doi.org/10. 1021/am400843d.

[148] G. Hemery, E. Garanger, S. Lecommandoux, A.D. Wong, E.R. Gillies, B. Pedrono, T Bayle, D. Jacob, O. Sandre, Thermosensitive polymer-grafted iron oxide nanoparticles studied by in situ dynamic light backscattering under magnetic hyperthermia, J. Phys. Appl. Phys. 48 (2015), 494001. https://doi.org/10.1088/0022-3727/48/49/ 494001.

[149] B.T. Luk, L. Zhang, Current advances in polymer-based nanotheranostics for cancer treatment and diagnosis, ACS Appl. Mater. Interfaces 6 (2014) 21859-21873, https://doi.org/10.1021/am5036225.

[150] J.K. Oh, R. Drumright, D.J. Siegwart, K. Matyjaszewski, The development of microgels/nanogels for drug delivery applications, Prog. Polym. Sci. 33 (2008) 448-477, https://doi.org/10.1016/j.progpolymsci.2008.01.002.

[151] M. Hamidi, A. Azadi, P. Rafiei, Hydrogel nanoparticles in drug delivery, Adv. Drug Deliv. Rev. 60 (2008) 1638-1649, https://doi.org/10.1016/j.addr.2008.08.002.

[152] T. Kubo, K. Hosoya, M. Nomachi, N. Tanaka, K. Kaya, Preparation of a novel molecularly imprinted polymer using a water-soluble crosslinking agent, Anal. Bioanal. Chem. 382 (2005) 1698-1701, https://doi.org/10.1007/s00216-005-3341-y.

[153] M. Chu, Y. Shao, J. Peng, X. Dai, H. Li, Q. Wu, D. Shi, Near-infrared laser light mediated cancer therapy by photothermal effect of Fe3O4 magnetic nanoparticles, Biomaterials 34 (2013) 4078-4088, https://doi.org/10.1016/j.biomaterials.2013.01. 086.

[154] S. Shen, S. Wang, R. Zheng, X. Zhu, X. Jiang, D. Fu, W. Yang, Magnetic nanoparticle clusters for photothermal therapy with near-infrared irradiation, Biomaterials 39 (2015) 67-74, https://doi.org/10.1016/j.biomaterials.2014.10.064.

[155] A. Plan Sangnier, S. Preveral, A. Curcio, A.K.A. Silva, C.T. Lefèvre, D. Pignol, Y Lalatonne, C. Wilhelm, Targeted thermal therapy with genetically engineered magnetite magnetosomes@RGD: Photothermia is far more efficient than magnetic hyperthermia, J. Control. Release 279 (2018) 271-281, https://doi.org/10.1016/j. jconrel.2018.04.036.

[156] G. Ku, M. Zhou, S. Song, Q. Huang, J. Hazle, C. Li, Copper Sulfide Nanoparticles as a New Class of Photoacoustic Contrast Agent for Deep Tissue Imaging at $1064 \mathrm{~nm}$, ACS Nano 6 (2012) 7489-7496, https://doi.org/10.1021/nn302782y.

[157] A.L. Antaris, H. Chen, K. Cheng, Y. Sun, G. Hong, C. Qu, S. Diao, Z. Deng, X. Hu, B. Zhang, X. Zhang, O.K. Yaghi, Z.R. Alamparambil, X. Hong, Z. Cheng, H. Dai, A small-molecule dye for NIR-II imaging, Nat. Mater. 15 (2015) 235, https://doi org/10.1038/nmat4476https://www.nature.com/articles/ nmat4476\#supplementary-information.

[158] Yuebin Li, Wei Lu, Oian Huang, Chun Li, Wei Chen, Copper sulfide nanoparticles for photothermal ablation of tumor cells, Nanomed. 5 (2010) 1161-1171, https://doi. org/10.2217/nnm.10.85. 